\title{
The intraperitoneal delivery of radiolabeled monoclonal antibodies: studies on the regional delivery advantage
}

\author{
Richard L. Wahl ${ }^{1}$, Jeffrey Barrett ${ }^{2}$, Onelio Geatti ${ }^{1^{*}}$, Monica Liebert ${ }^{1}$, Barry S. Wilson ${ }^{3^{* *}}$, Susan Fisher ${ }^{1}$, \\ and John G. Wagner ${ }^{2}$ \begin{abstract}
${ }^{2}$ University of Michigan Medical Center, College of Pharmacy and Upjohn Center for Clinical Pharmacology, Ann Arbor, Michigan, USA
\end{abstract} \\ ${ }^{1}$ University of Michigan Medical Center, Department of Internal Medicine, Division of Nuclear Medicine, Ann Arbor, Michigan, USA \\ ${ }^{3}$ University of Michigan Medical Center, Department of Pathology, Ann Arbor, Michigan, USA
}

Summary. The i.p. delivery of murine monoclonal antibody was compared with i.v. delivery in normal mice and rats, in normal nude mice and in those with i.p. human ovarian carcinoma xenografts. In normal rats, all classes of antibodies and antibody fragments evaluated were cleared from the peritoneal cavity at comparable rates. The regional delivery $\left(\mathrm{Rd}^{1}\right)$ advantage to the peritoneal cavity following i.p. delivery was thus most dependent on the rate of clearance of the antibody or fragment from the blood stream. Determining the exact i.p. delivery advantage was problematic due to the difficulty in reliably obtaining peritoneal fluid later than 9-10 $\mathrm{h}$ after i.p. injection in normal animals. During the first $9 \mathrm{~h}$ following i.p. injection, the $\operatorname{Rd}(0-9 / 0-9)$ was, for a murine IgG2ak Fab > $\mathrm{F}\left(\mathrm{ab}^{\prime}\right)_{2}>\operatorname{IgG}$ (at $13.6>10>7.9$ ). Two murine IgMs evaluated differed in $\operatorname{Rd}(0-9)$ at 27.1 and 9.2 respectively. When blood levels were extrapolated to infinity, these Rd $(0-9 / \infty)$ values were considerably lower with the Fab having the highest $\mathrm{Rd}$ at 4.67 . The i.p. Rd advantage was almost solely due to the i.p. antibody levels seen in the first $24 \mathrm{~h}$ after injection, as after that time, blood levels become comparable to those seen following i.v. injection. Normal tissues obtained at sacrifice 5-7 days after i.p. injection. Normal tissues obtained at sacrifice 5-7 days after i.p. or i.v. injection in rats showed comparable levels of radioantibody activity, whether the injection was i.p. or i.v. (except for higher diaphragmatic levels following i.p. delivery). In nude mice with i.p. human-derived ovarian tumors, intact IgG clearance from the peritoneal cavity to the blood was considerably slower than in normal animals, and early i.p. tumor uptake of specific antibody was significantly higher than that following i.v. antibody delivery. With higher early tumor uptake and lower systemic exposure, early tumor/nontumor ratios were significantly greater than

\footnotetext{
${ }^{1} \mathrm{Rd}$ is area under the curve (AUC) for peritoneal fluid activity / AUC for blood radioactivity. $\mathrm{Rd}(0-9 / 0-9)$ is the Rd measured from 0 to $9 \mathrm{~h}$ for both peritoneal fluid and blood. $\mathrm{Rd}(0-9 / \infty)$ is the conservative estimate of Rd with i.p. fluid AUC measured to $9 \mathrm{~h}$, with blood levels extrapolated to infinity. $\mathrm{Rd}_{2}$ is $\mathrm{Rd} /(\mathrm{AUC}$ i.p. fluid (0-9)/AUC blood (0-9)) after i.v. injection.

* Present address: Istituto di Medicina Nuclear, Ospedale Civile, Udine, Italy

** Present address: Hybritech Incorporated, Department of Cell Biology, San Diego, CA, USA

Offprint requests to: Richard L. Wahl, University of Michigan Medical Center, Division of Nuclear Medicine, Box 0028, 1500 East Medical Center Drive, Ann Arbor, MI 48109-0028, USA
}

those for i.v. delivery, though not beyond $48 \mathrm{~h}$ after i.p. injection. This study demonstrates the pharmacokinetic rationale for i.p. monoclonal antibody delivery, especially for agents cleared rapidly from the blood, such as antibody fragments. In addition, definite i.p. delivery benefit for antibody specific to i.p. tumors in the i.p. ovarian cancer system was shown soon after injection. These data regarding i.p. antibody delivery should be useful in rationally planning diagnostic and therapeutic studies involving the i.p. delivery of unmodified and immunoconjugated monoclonal antibodies.

\section{Introduction}

Regional delivery (Rd) of chemotherapeutic agents to the peritoneal and other cavities has been used in the treatment of malignant diseases restricted to such spaces, such as ovarian carcinoma $[7,11,20]$. With the development of monoclonal antibodies reactive with ovarian carcinoma, some of which when radiolabeled are capable of immunoimaging such tumors, the i.v. and more recently the i.p. routes of antibody delivery to such regionally limited diseases have been explored $[2,4,9,10,25,27]$. While there has been preliminary clinical utilization of the i.p. delivery route for ovarian cancer therapy in humans, relatively little is known about the clearance rate of monoclonal antibodies from the peritoneal cavity.

It is clear that higher concentrations of radiolabeled antibodies present in a given region will result in higher binding to target antigens in that region, due to binding kinetic considerations [14]. We have recently shown for radioiodinated intact murine IgG2ak, that increased antibody concentration compared to blood levels exists in the peritoneal cavity of rats following i.p. antibody administration $[21,24]$. We also showed that this i.p. delivery advantage could be further enhanced by accelerating the clearance of the intact $\operatorname{IgG}$ from the blood stream using a systemically administered polyclonal anti-mouse antibody [21]. Through such a manipulation, the Rd advantage following i.p. administration could be increased by approximately $50 \%$ in the first $10 \mathrm{~h}$ after injection.

Since quite marked differences exist among the blood clearance rates and tumor imaging properties of intact monoclonal antibodies and monoclonal antibody fragments following intravascular delivery, it is possible that similar differences in clearance may exist for i.p. delivered monoclonal antibodies $[3,5,23]$ and that there might be 
large differences in the Rd advantage when given i.p. The present study was conducted to determine the extent of the $\mathrm{Rd}$ advantage to the peritoneal space for monoclonal antibodies, as well as the influence of antibody class and fragmentation on the delivery advantage. This report also evaluates the influence of i.p. human tumor xenografts on antibody clearance from the peritoneal space and examines the extent of localization improvement of specific antibody to i.p. human ovarian carcinoma xenografts following i.p. versus i.v. delivery.

\section{Material and methods}

Monoclonal antibodies. The $225.28 \mathrm{~S}$ is an IgG2ak murine monoclonal antibody reactive with the high molecular weight antigen of melanoma [33]. Hybridoma cells producing this reagent were grown in pristane-primed (Aldrich) $\mathrm{Balb} / \mathrm{c}$ mice as ascites, and then purified by staphylococcal protein A chromatography [8]. Then $225.28 \mathrm{~S} \mathrm{~F}\left(\mathrm{ab}^{\prime}\right)_{2}$ fragments were prepared by $2 \%$ pepsin digestion in $\mathrm{pH} 4.2$ acetate buffer, with subsequent purification by dialysis and on a staphylococcal protein A column $[8,15,23]$. The $225.28 \mathrm{~S}$ Fab fragment was prepared by $2 \%$ papain digestion with purification of the Fab from the Fc on a staphylococcal protein A column, followed by additional purification using TSK sizing HPLC [16]. FT166 is an IgM of murine origin, which was purified by DEAE chromatography from mouse ascites (Liebert et al. unpublished data) [32]. UPC-10 is an IgG2a monoclonal antibody purchased in purified form (Bionetics Research, Charleston, $\mathrm{SC}$ ). BA-1 is a murine IgM, (generously provided by $\mathrm{Hy}-$ britech, LaJolla, Calif.) [1], reactive with human B-cells which was purified from carrier human albumin protein using TSK sizing HPLC. 5G6.4 is an IgG2a murine monoclonal antibody with preferential reactivity with ovarian and other epithelial cancers [27]. It was purified from ascites by staphylococcal protein A chromatography. None of these murine antibodies are known to cross-react with normal mouse or rat tissues. The molecular weight and purity of these reagents was verified on $7.5 \%$ sodium dodecyl sulfate (SDS) polyacrylamide gels with and without 2-mercaptoethanol [12].

Radiolabeling. All labelings were conducted using ${ }^{131} \mathrm{I}$ or ${ }^{125}$ I (New England Nuclear, Boston, Mass.), by the Iodobead or Iodogen method (Pierce Chemical, Rockford, Ill.) [13]. In general, $1 \mathrm{mCi}$ was used to label $50-100 \mu \mathrm{g}$ of antibody protein, and free iodine was removed from the mixture by Biogel P-60 sizing chromatography (Bio-Rad Laboratories, Richmond, Calif.). Iodine incorporation was in the $30 \%$ to $70 \%$ range. Freedom from iodine contamination was demonstrated by thin layer chromatography with $50 \%$ ethyl acetate and 50\% ethanol [26]. In tumor-specific antibody studies the proportion of iodinated $5 \mathrm{G} 6.4$ or iodinated UPC-10 binding to $1-2 \times 10^{6}$ HTB77 antigen-positive tumor cells in a $1-\mathrm{h}$ incubation was also assessed in a direct cell binding assay [26].

Animal studies. Adult, approximately $180-250 \mathrm{~g}$, female Sprague-Dawley rats were sedated with pentobarbital given i.p. $(40 \mathrm{mg} / \mathrm{kg})$. The animals were then placed in a supine position and a portion of their ventral abdomen shaved. The skin over the midline of the abdomen was opened for about $1 \mathrm{~cm}$, with a portion of parietal perito- neum exposed. The i.p. injections of antibody were performed with a 27 -gauge needle attached to a $20 \mathrm{ml}$ syringe under direct visualization. Preliminary studies using India ink in saline demonstrated that this approach resulted in i.p. fluid delivery without significant leakage. Peritoneal fluid was subsequently sampled (50-100 $\mu$ l aliquots) using a tuberculin syringe fitted with a 28 -gauge needle (under direct visualization). The i.v. injections were carried out by direct cannulation of the femoral vein with a 28 -gauge needle after an incision had been made in the skin overlying the vein.

In studies using i.p. tumor-bearing nude mice (approximately 8-12-week-old tumors), the ${ }^{125}$ I $5 \mathrm{G} 6.4$ antibody was given either i. p. or i.v. with animal sacrifice $4,24,48$, or $120 \mathrm{~h}$ later. Uptake in i.p. tumor foci (HTB77 IP3 line of human ovarian cancer) [31] and blood was compared between delivery routes (i.p. or i.v.). In addition, a dual-label experiment comparing simultaneously i.p. administered 5G6.4 and UPC-10 was conducted to confirm the specificity of tumor uptake. The rate of i.p. clearance of the nonspecific IgG2ak, UPC-10, was also studied in normal nude mice, nude mice with i.p. ovarian tumors, and in healthy BALB/c mice without such tumors. Gamma imaging following i.p. administration was also performed using a large field of view gamma camera equipped with a highenergy parallel hole or a pinhole collimator in selected instances. The images were digitally recorded in a dedicated computer for subsequent display and analysis. All images were performed using a $20 \%$ window centered at $364 \mathrm{KeV}$.

Time course experiments. In experiments evaluating i.p. antibody delivery in normal rats, groups of 3-7 adult female rats were injected i.p. with approximately $5-20 \mu \mathrm{Ci}$ of labeled antibody $(0.2-1 \mu \mathrm{g})$ in a total volume of $20 \mathrm{ml}$ of warm, $0.01 \mathrm{M}$ phophate-buffered saline, $\mathrm{pH} 7.0$. The $20 \mathrm{ml}$ volume was chosen, as some studies have suggested that a large i.p. fluid volume is useful in assuring uniform i.p. drug distribution [18]. Sequential blood samplings from the tail vein, and peritoneal fluid samplings by direct removal of peritoneal fluid using a 28 -gauge needle attached to a syringe were accomplished, with weighing and gamma counting of peritoneal fluid and blood. Peritoneal fluid could not commonly be obtained beyond $9-15 \mathrm{~h}$ after injection, due to resorption of fluid, particularly in the nontumor-bearing animals. In the time course experiments in rats, the animals were kept sedated by occasional (every 2-6 h) small $(\simeq 100 \mu \mathrm{L})$, i.p. boosts of pentobarbital during the first $9-10 \mathrm{~h}$ of the study. The animals were then allowed to recover, with additional blood and (when possible) peritoneal fluid samples obtained up to 1-7 days after injection, during brief sedation with ether. Animals were sacrificed at the conclusion of the study when normal organs were weighed and counted.

The experiments evaluating i.v. antibody delivery were very similar, with the exception that the radiolabeled antibody was given by femoral vein injection, while $20 \mathrm{ml}$ of warm phosphate-buffered saline, devoid of antibody, was given i.p. Samplings of blood and peritoneal fluid, as well as normal organs at sacrifice, were performed in an identical fashion. In several experiments, a dual-label approach was used [17].

These experiments were performed for all antibodies and fragments (except that the UPC-10 (data previously reported) [21] and BA-1 were studied only following i.p. 
administration and then to only $24 \mathrm{~h}$ after injection). The data were corrected for decay, and plotted as a time activity curve for the peritoneal cavity, and the blood. The Rd advantage was calculated for the first $9 \mathrm{~h}$ of the study (and to infinity where data were available) by measuring the area under the curve (AUC) for i.p. antibody delivery to the peritoneal cavity and the blood as follows [18]:

$$
R d=\frac{\text { AUC peritoneal cavity }}{\text { AUC blood }}
$$

Due to difficulty in computer fitting the terminal portion of the i.p. activity curves and due to difficulty in obtaining fluid reliably beyond $9-10 \mathrm{~h}$ in nontumor-bearing animals, a very conservative estimate of $R d$ to infinity $(\operatorname{Rd} 0-9 / \infty)$ was also made by dividing the measured i.p. antibody AUC to $9 \mathrm{~h}$ by the blood AUC to infinity. An Rd 0-9/0-9 was also calculated, comparing the AUC i.p. to $9 \mathrm{~h}$ to the AUC $0-9 \mathrm{~h}$ for blood. A log-linear trapezoidal best fit computer program was used to fit curves and estimate AUCs. When i.p. fluid could be obtained up to $15 \mathrm{~h}$, a Rd 0-15/0-15 was also determined. Another estimate of regional delivery advantage, $\mathrm{Rd}_{2}$ was determined as follows [7]:

$$
\operatorname{Rd}_{2}(0-9)=\operatorname{Rd}(0-9 / 0-9)
$$

$\frac{\text { AUC peritoneal cavity (0-9) }}{\text { AUC blood }(0-9)}$ with i.v. administration

Tissue distributions. Tissue biodistributions of the radiolabeled antibodies and fragments following i.v. and i.p. delivery routes were determined at sacrifice 4-7 days after antibody injection in rats, and at times ranging from $4 \mathrm{~h}$ to 5 days in nude mice with tumors and BALB/c mice, when major organs and/or tumors were removed, weighed, blotted, and counted with percent kilogram dose per gram determined using standard tissue handling techniques.

Absorption rate constant determination. A compartmental analysis was performed on the individual i.p. concentration time profiles using the program AUTOAN [19]. In those instances in which a model could be used to fit the data, the absorption rate constant was calculated for the antibodies administered via i.p. injection. In most cases, a one compartment model with first order absorption was the model of choice.

Statistical analysis. Differences among groups of Rds were assessed by analysis of variance or by the Fishers protected least square difference method. A computerized best-fit graphic system allowing for multiexponential curve fitting was used to determine segmental terminal phase $t^{1 / 2} \mathrm{~s}$. Oneway analysis of variance, the Scheffe $F$-test and Dunnett $t$-tests were used in the analysis of the absorption rate constant data.

\section{Results}

\section{Effects of class and fragmentation in normal rats}

Clearance curves for the varying antibodies and fragments from the blood of healthy rats following i.v. injection are shown in Fig. 1. Note that the terminal phase $t^{1} / 2$ of blood clearance of intact IgG 225.28S (52.3 h \pm 6.09 standard error of mean) was longer than its $F\left(a b^{\prime}\right)_{2}(14.16 \pm 0.65)$, which was longer than the clearance of Fab $(8.7 \pm 1.39)$ $(P<0.005)$. IgM FT166 cleared quite rapidly in these experiments, with a terminal phase blood $t^{1 / 2}$ comparable to $\mathrm{F}\left(\mathrm{ab}^{\prime}\right)_{2}(12.6 \pm 1.20)$, but slower than Fab $(P<0.05)$. Decreasing blood concentrations were generally fitted by bi or triexponential equations. Blood samples were not collected beyond $24 \mathrm{~h}$ from the rats given UPC-10 i.p., and the terminal phase blood $t^{1} / 2$ could not be determined.

The time course of radioantibody concentration in the peritoneal cavity following i.p. injection is shown graphically in Fig. 2. These profiles are quite similar to one another in that there was little overall drop in i.p. antibody concentration seen, except after $15 \mathrm{~h}$ when only a few samples could be obtained from normal animals. Higher, more

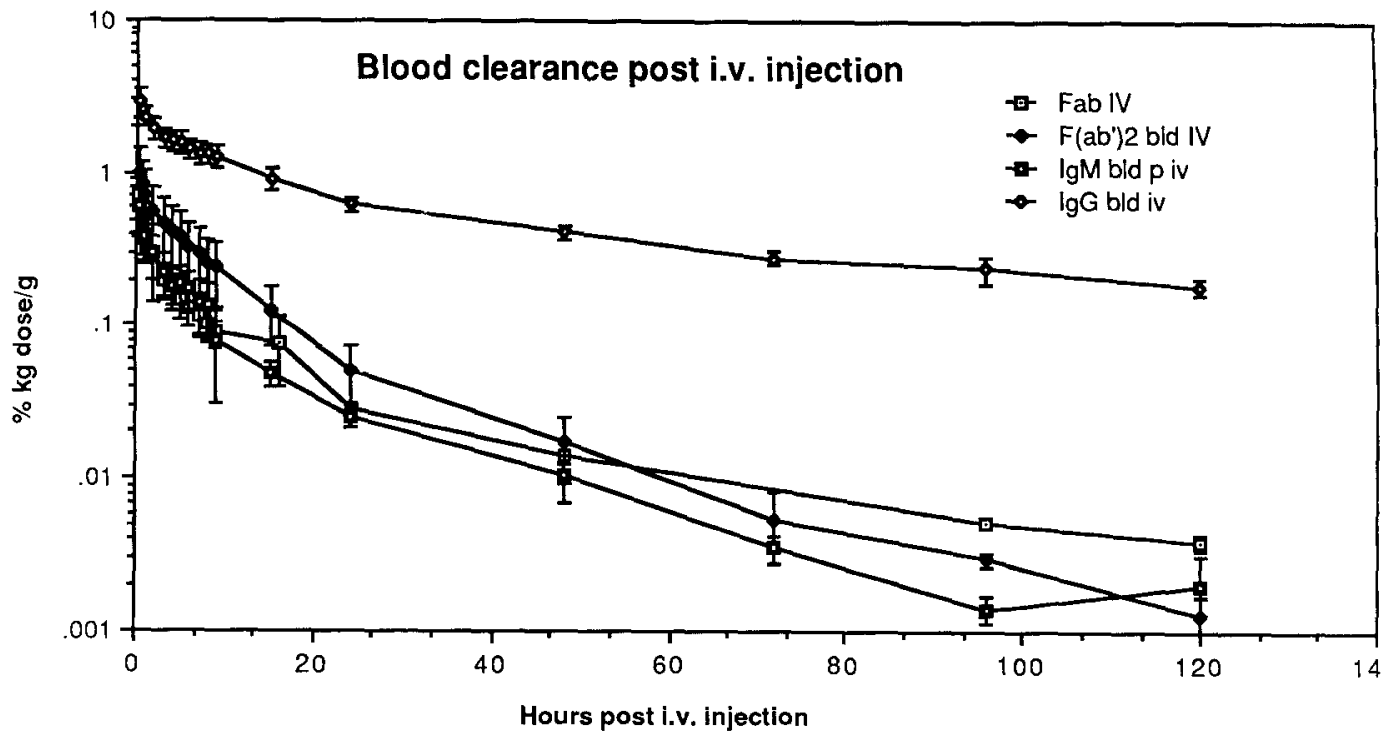

Fig. 1. Clearance of murine antibodies and fragments from the rat blood stream following i.v. injection (mean of $3-5$ animals \pm standard error of mean (SEM) shown, 225.28S Fab, F(ab') ${ }_{2}$ and intact, as well as FT166 IgM). Note fast initial clearance and slower later phase clearance for these moieties 


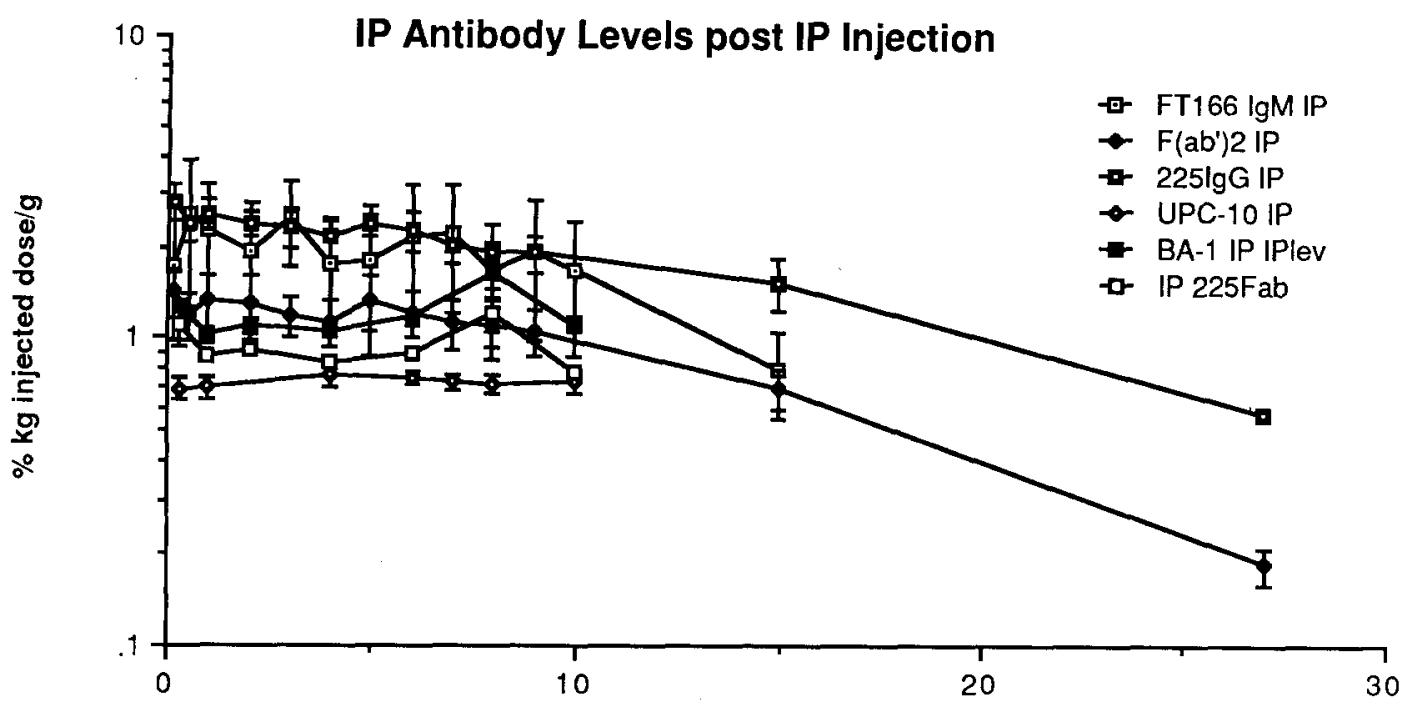

\begin{abstract}
Hours
Fig. 2. Clearance of the same reagents as in Fig. 1, as well as BA-1 IgM and UPC-10 IgG2a, following i.p. administration to adult rats. Note the relatively slow decline. Mean \% kg injected dose/g \pm SEM for 3-5 animals is plotted. Peritoneal fluid was generally resorbed sufficiently by $9-15 \mathrm{~h}$ into the study so that peritoneal fluid sampling became impossible, thus only limited peritoneal fluid data are available beyond these times
\end{abstract}

prolonged levels of activity were achieved i.p., as compared with blood levels, following i.p. delivery. The $t^{1 / 2}$ for clearance from the peritoneal cavity was longer than the measured $t^{1 / 2}$ of clearance from the blood, but due to the difficulty in obtaining reliable peritoneal fluid values beyond $10-15 \mathrm{~h}$, it was difficult to determine an exact $t^{1 / 2}$ for peritoneal clearance. In fact, in some animals, peritoneal fluid radioantibody levels rose during the period of observation presumedly related to faster fluid than protein absorption. The measured blood $t^{1 / 2 s}$ immediately after i.v. injection were: 1.95, 3, 6.4, and $1.2 \mathrm{~h}$ for FT166 IgM, $\mathrm{F}\left(\mathrm{ab}^{\prime}\right)_{2}, \operatorname{IgG} 225.28 \mathrm{~S}$, and $225.28 \mathrm{~S}$ Fab respectively (all phase $t^{1 / 2}$ ), which were shorter than the $t^{1 / 2 s}$ for peritoneal fluid clearance. These differences in clearance rates between i.p. levels and blood levels soon after injection appeared to be the major determinants of the Rd advantage to the peritoneal cavity. In selected instances, blood samples 1 or more days after i.p. antibody injection showed the circulating antibody to be identical to the species injected i.p. using SDS gels.

The relative concentrations of antibody radioactivity in peritoneal fluid, compared with blood, following the i.p. injection route are shown in Fig. 3a-f, where a higher level of radioantibody activity was seen in the peritoneal cavity than in the blood at all times during which fluid could be reliably sampled following i.p. antibody injection. In occasional instances where peritoneal fluid could be obtained $24 \mathrm{~h}$ or more after injection the i.p. fluid levels had dropped to near blood levels indicating that the i.p. delivery advantage had largely disappeared $24 \mathrm{~h}$ after injection. In Fig. 3, the mean level of radioantibody in the blood and peritoneal fluid following i.v. injection of the same antibody preparation in similar animal groups is plotted. The radioantibody levels in the peritoneal fluid following i.p. delivery were also generally higher than maximal levels achieved in the blood following i.v. delivery of the same amount of radioantibody. In addition, the
AUC for i.p. antibody administration to the peritoneum was visibly greater than that of blood following i.v. delivery in the time peritoneal fluid could be sampled. By contrast, radioantibody levels in the peritoneal cavity following i.v. delivery, and blood levels following i.p. delivery were both quite low in the first $10 \mathrm{~h}$ after injection. In the first $9 \mathrm{~h}$ following injection, 50-110 times more antibody reached the peritoneal cavity (for the same blood level) following i.p. than following i.v. administration $\left(\mathrm{Rd}_{2}\right)$. The mean $\mathrm{Rd}$ advantage expressed in a variety of ways for each antibody or fragment is listed in Table 1. Note that a substantial $\mathrm{Rd}$ advantage existed for each reagent, when assessed in the first $9 \mathrm{~h}$ after i.p. injection ( $\mathrm{Rd} 0-9 / 0-9$ ).

The Rd (0-9/0-9) or the level of i.p. antibody concentration over time (AUC i.p.) to the peritoneal cavity divided by systemic levels (AUC blood) was significantly elevated $(>1)$ for all antibodies and fragments, but was most elevated for FT166 IgM [Rd (0-9/0-9) = 27.16 \pm 3.1$]$. This $\operatorname{Rd}(0-9 / 0-9)$ for IgM FT166 was significantly higher than for 225.28S Fab $(13.63 \pm 0.98)(P<0.01)$, which was higher than 225.28S F(ab') $(10.04 \pm 0.72, P<0.025)$, which in turn was higher than $225.28 \mathrm{~S} \operatorname{IgG}(\mathrm{Rd}=7.85 \pm 0.71)$ $(P<0.05)$. The BA-1 IgM had a lower $0-10 \mathrm{~h}$ Rd than the FT166 at $(9.15 \pm 3.01)$. The Rd for UPC-10 was nearly identical to that for the 225.28S $(6.2 \pm 1.09)$. Peritoneal fluid was frequently difficult to collect beyond $9-10 \mathrm{~h}$ after injection in normal rats due to resorption, but it was apparent that the Rd over $15 \mathrm{~h}$ was less than over 9-10 h (where samples were available, $P<0.005$ ), largely due to rising blood antibody levels at this time.

While the $\mathrm{Rd}(0-9 / 0-9)$ was measurable for each reagent, the more pharmacokinetically correct approach to $\mathrm{Rd}$ calculation is to integrate the AUC ( $\mathrm{t}=0$ to infinity) for peritoneal fluid following i.p. delivery, and to divide this by the similar AUC ( $t=0$ to infinity) for blood. This approach was, unfortunately, not feasible for the the peritoneal fluid due to the difficulty in determining i.p. fluid 

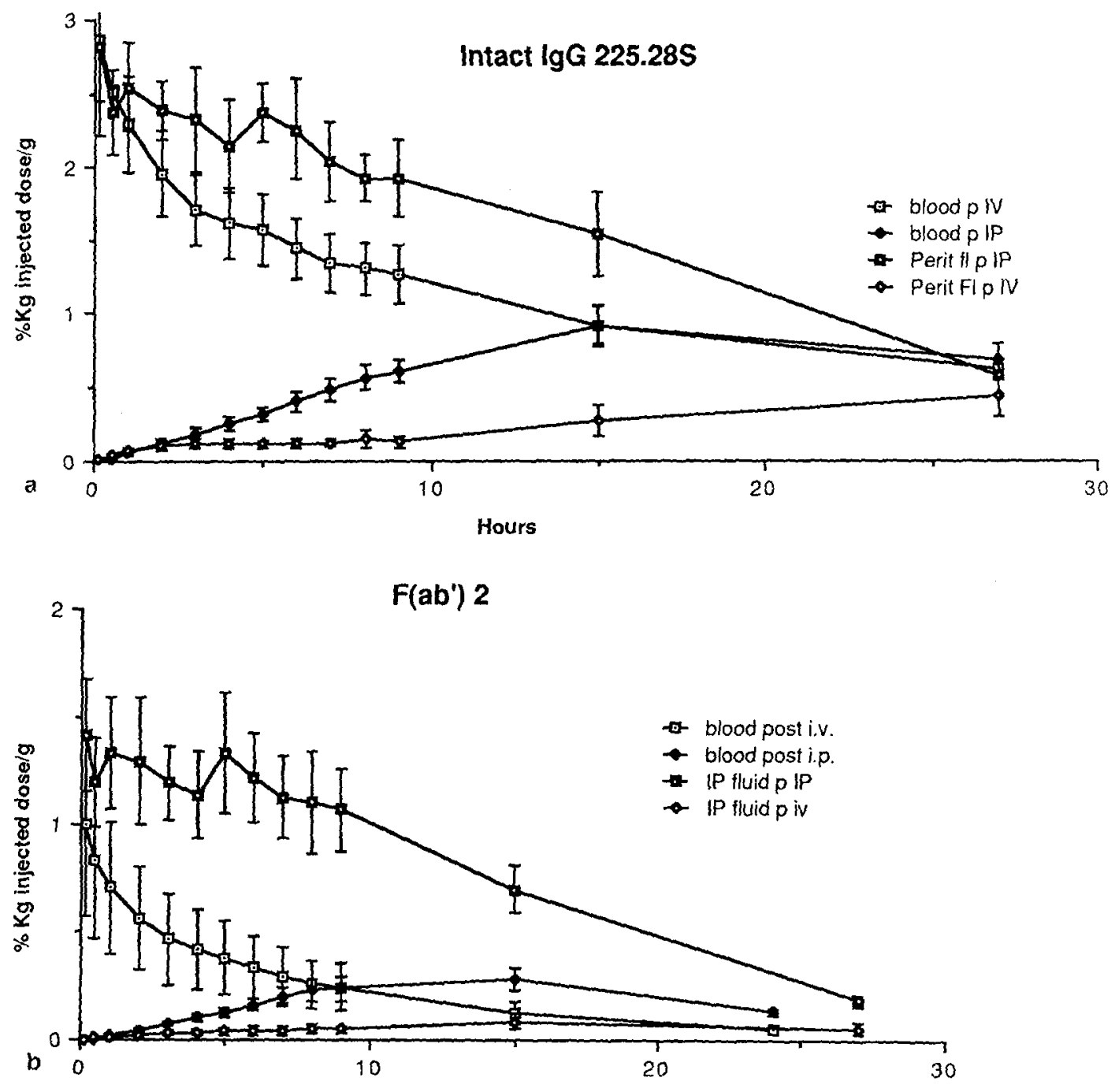

Hours post injection

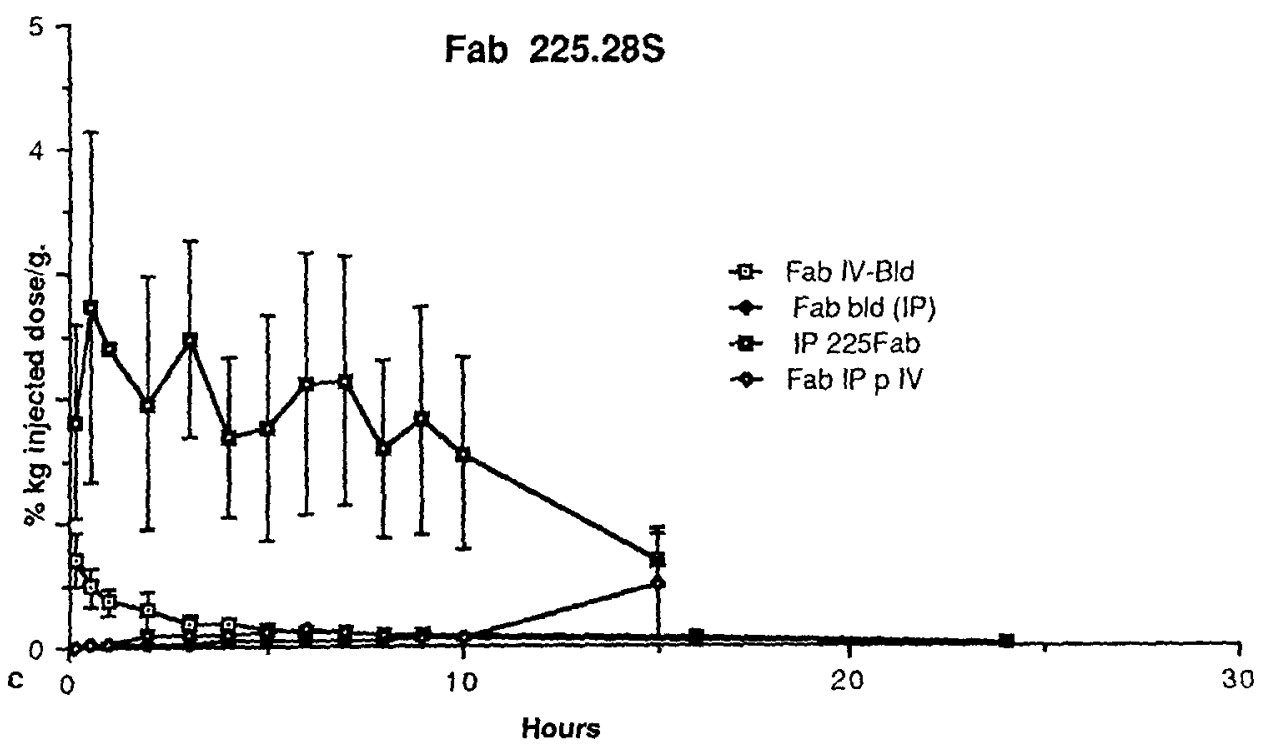

Fig. $3 a-c$ 

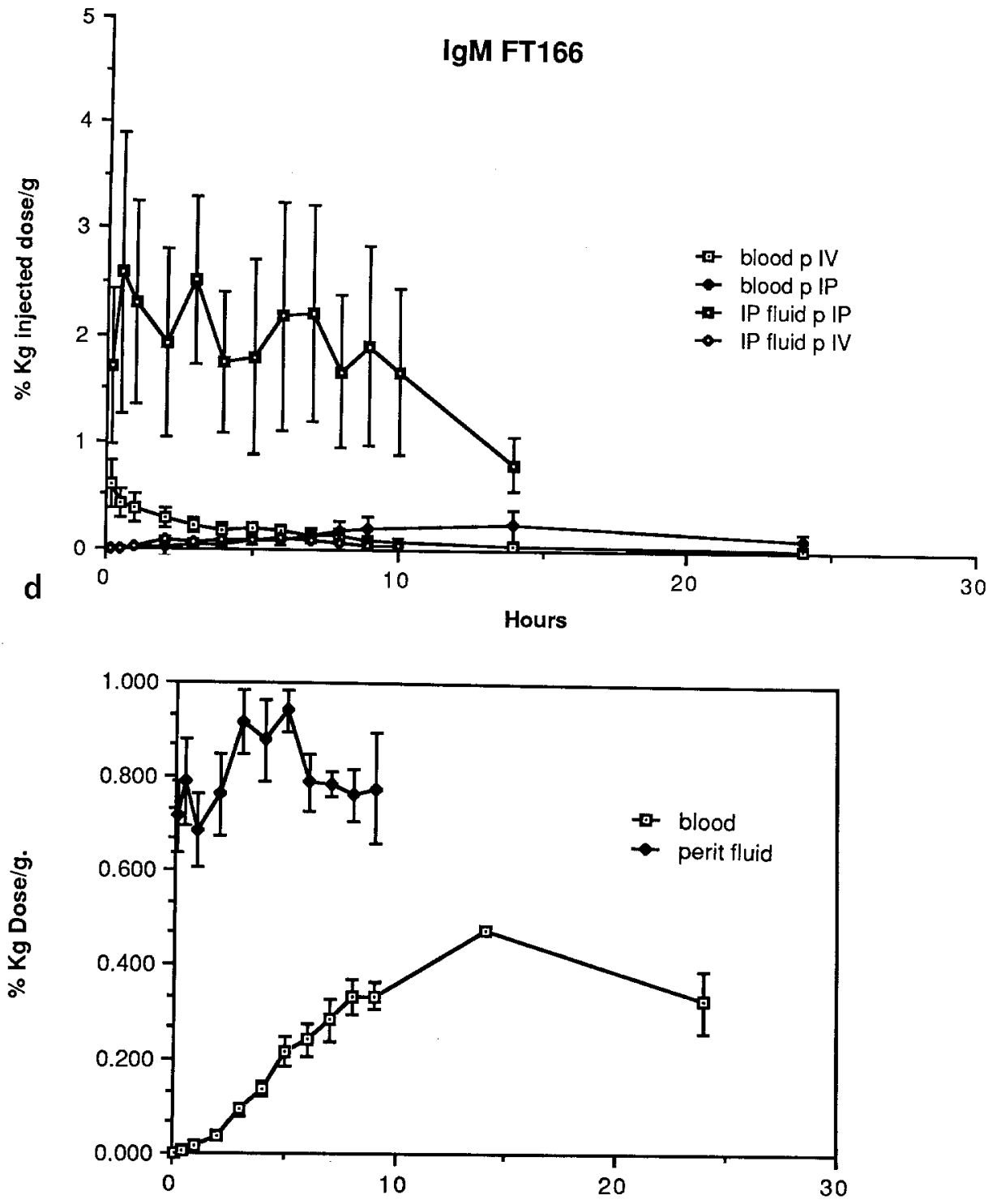

e

Hours post IP injection

BA-1 IgM

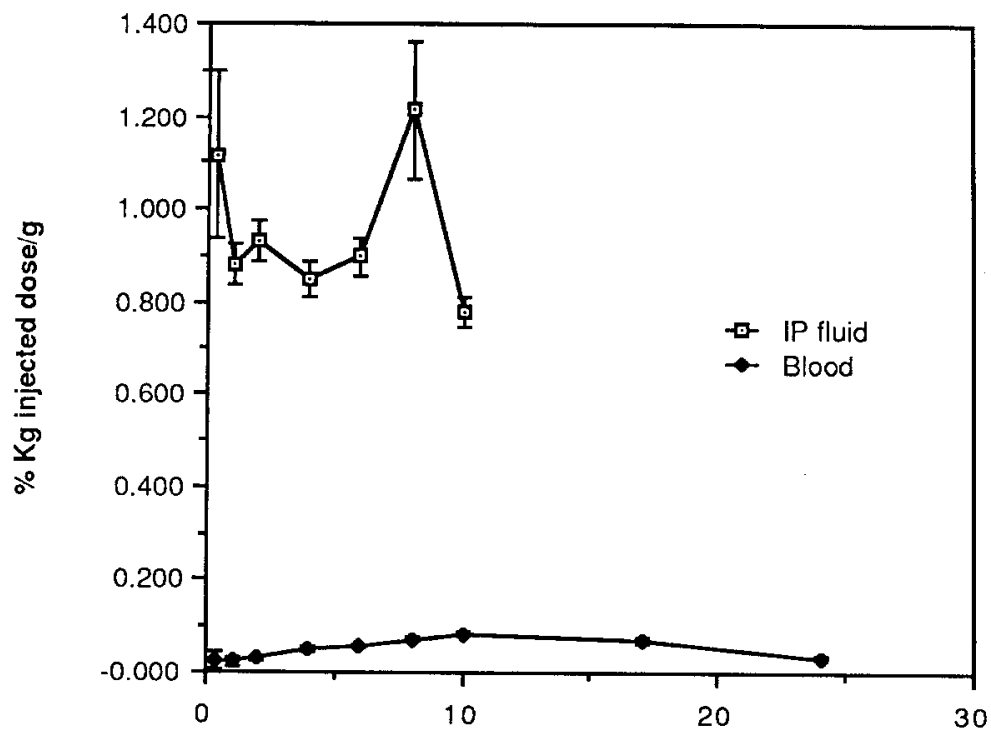

Fig. 3 a-f. (a) Clearance of intact $\operatorname{IgG} 2 \mathrm{a}$, 225.28S; (b) F(ab') , 225.28S; (c) Fab, 225.28S; (d) IgM, FT166; (e) IgG2a, UPC-10; and (f) IgM, BA-1 from the blood and from the peritoneal cavity following i.p. (a-f) and i.v. (a-d) delivery of equal amounts of radioantibody. The mean of 3-5 animals \pm SEM is plotted. Note that in all instances the highest levels were achieved and maintained longest in the peritoneal cavity following i.p. toneal administration, and that the lowest levels seen were those of radioantibody reaching peritoneal fluid following i.v. delivery. Note that beyond $10-15 \mathrm{~h}$, peritoneal fluid was difficult to reliably obtain, but when it was obtained its level of activity following i.p. delivery approached the blood level 
Table 1. Area under curve peritoneal fluid post IP delivery Area under curve blood post IP delivery $=R d$
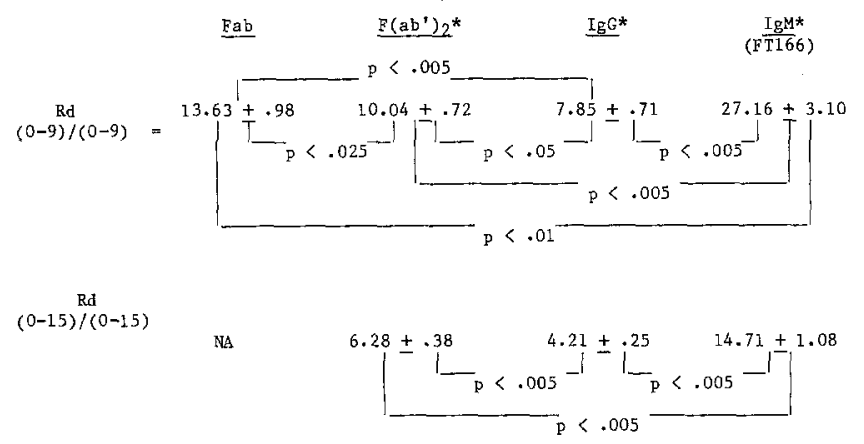

Rd $(0-9) / \infty$

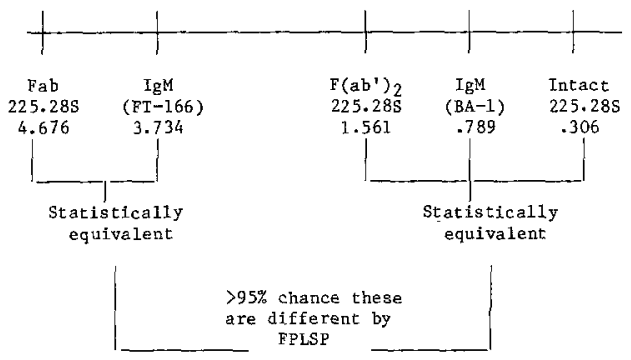

levels $9-15 \mathrm{~h}$ after injection and the fact that in several instances, a downslope was not seen in the i.p. radioantibody activity in the time observed (making it impossible to extrapolate i.p. levels to infinity). For this reasons, it was necessary to express Rd to infinity as the measured AUC i.p. from $0-9 \mathrm{~h}$ and then assume that i.p. antibody levels fell immediately to zero. Terminal blood $t^{1 / 2} \mathrm{~s}$ were easily estimated, however, and the AUC zero to infinity for blood could be determined. Thus, the $(\operatorname{Rd} 0-9 / \infty)$ was a clear underestimate of $\mathrm{Rd}$, but did allow for another means of comparison among the antibodies. These data showed the $\operatorname{Rd}(0-9 / \infty)$ of Fab of 225 and the IgM FT166 to be statistically comparable, while the intact $\mathrm{IgG}$, 225.28S; IgM BA-1, and the $F\left(a b^{\prime}\right)_{2}$ of 225.28 S were similar to one another and significantly ( $>95 \%$ chance) less than the $\mathrm{Rd} 0-9 / \infty \mathrm{Fab}$ of $225.28 \mathrm{~S}$ and FT166. The terminal phase blood $t^{1 / 2}$ of the animals given UPC- 10 was not determined in these studies and no Rd zero to infinity can be expressed. It is of interest that by this overly conservative measurement, no definite Rd advantage was seen to the peritoneal cavity for IgG (225.28S) or BA-1 (i.e., Rd $0-9 / \infty<1)$. As can be seen in Fig. $3 a$ and in Fig. 4a, for intact antibody, since blood levels were comparable from $15 \mathrm{~h}$ on, and i.p. levels were greater after i.p. than i.v. delivery a Rd advantage for intact IgG must be present, but is not apparent due to the conservative estimation approach used when $\operatorname{Rd} 0-9 / \infty$ is used. Absorption rate constants from the peritoneal cavity were statistically equivalent among the antibodies and fragments used (Table 2), and the $\mathrm{Rd}$ was most dependent on the systemic clearance rate of the antibody or fragment used.

Tissue distributions of the four radiolabeled antibodies and fragments in normal rats sacrificed at 5-7 days after injection, are shown in Table 3 . The antibodies used had no known binding to rat tissues, and resulted in relatively similar tissue levels independent of delivery route at these late times, though with FT166 IgM the i.p. route tended to give somewhat lower systemic antibody levels than the i.v. route. In all cases, the diaphragm maintained significantly higher levels of radioactivity following i.p. delivery than the levels in that tissue following i.v. administered antibody $(P<0.001)$. Other than the diaphragm, the similarity in tissue uptake for extraabdominal tissues at late times was not unexpected, due to the similarity in blood levels achieved by the i.p. or i.v. routes for each radioantibody (Fig. $4 \mathrm{a}-\mathrm{d}$ ) at $15 \mathrm{~h}$ and later following injection. It is obvious in these normal animals that systemic exposure to radiolabeled antibody, at later times after injection, was quite comparable following the i.p. and i.v. delivery routes.

\section{Tumor bearing animals}

While normal rats are a useful system to evaluate the clearance of antibodies and fragments from the peritoneal cavity, it is important to determine if the pharmacokinetic differences for nonspecific antibody between i.p. and i.v. delivery extend to the behavior of specific antibody in animals with antigen-positive i.p. tumor. For this reason, we evaluated the delivery to blood and tumor of radiolabeled tumor-specific and nonspecific antibodies following i.p. or i.v. injection into normal BALB/c mice, nude mice without tumors, and nude mice with i.p. ovarian tumors.

Figure 5 a-d demonstrates the gamma scan appearance of groups of normal nude mice and HTB77 IP3 tumorbearing mice following i.p. or i.v. injection of ${ }^{131} \mathrm{I} 5 \mathrm{G} 6.4$, specific antibody, at $4 \mathrm{~h}$ after injection $(\mathrm{a}=$ normal nude mice after i.p. delivery, $b=$ normal nude mice after i.v. delivery, $\mathrm{c}=$ IP3 tumor-positive mice after i.p. delivery, and $\mathrm{d}=$ IP3 tumor-positive after i.v. delivery). Note that in mice given 5G6.4 i.p., there was far more whole body activity in the group without tumors (5a) than in group-5c, with tumor, indicating faster egress from the peritoneal cavity to the blood. In fact, the normal nude mice with i.p. antibody delivery (5a) looked very similar at $4 \mathrm{~h}$ to the normal mice with i.v. antibody delivery ( 5 b) and the tumor-bearing mice after i.v. delivery (5d). Only the tumorbearing animals after i.p. injection had high level i.p. antibody retention $(5 \mathrm{c})$. In parallel experiments, this slower egress was demonstrated for specific antibody 5G6.4 and for nonspecific antibody UPC-10 given i.p. to normal and tumor-bearing animals by blood sampling at several times points (Fig. 6a). The blood levels of antibody in the HTB77 IP3 tumor-bearing animals rose more slowly, and peaked later than in the normal animals (Fig. 6a and b). The absorption rate constants for UPC-10 or $5 \mathrm{G} 6.4$ in tumor-bearing mice were significantly less than for normals (Table $6, P<0.005$ ). There was no significant difference between absorption rate constants for $5 \mathrm{G} 6.4$ or UPC10 (Table 6). Nontarget organ tissue levels of radioactivity per gram were similar at sacrifice 3 days after antibody injection in normal and tumor-bearing animals (Fig. 7).

Following i.p. or i.v. injection of ${ }^{125}$ I 5 G6.4 in animals with i.p. foci of human ovarian cancer HTB77 IP3, there was greater absolute tumor uptake following the i.p. route of delivery than the i.v. route when examined $4 \mathrm{~h}$ after antibody injection (Fig. 8a and Table 4). Table 4 illustrates that antibody uptake was clearly higher in tumor after i.p. than i.v. delivery $(P<0.025)$, while uptake in nontarget tissues was significantly less in the first $24 \mathrm{~h}$ following i.p. delivery. While tumor uptakes were equivalent at 24-120 h, there was less systemic (renal, lung) activity at $24 \mathrm{~h}$ follow- 

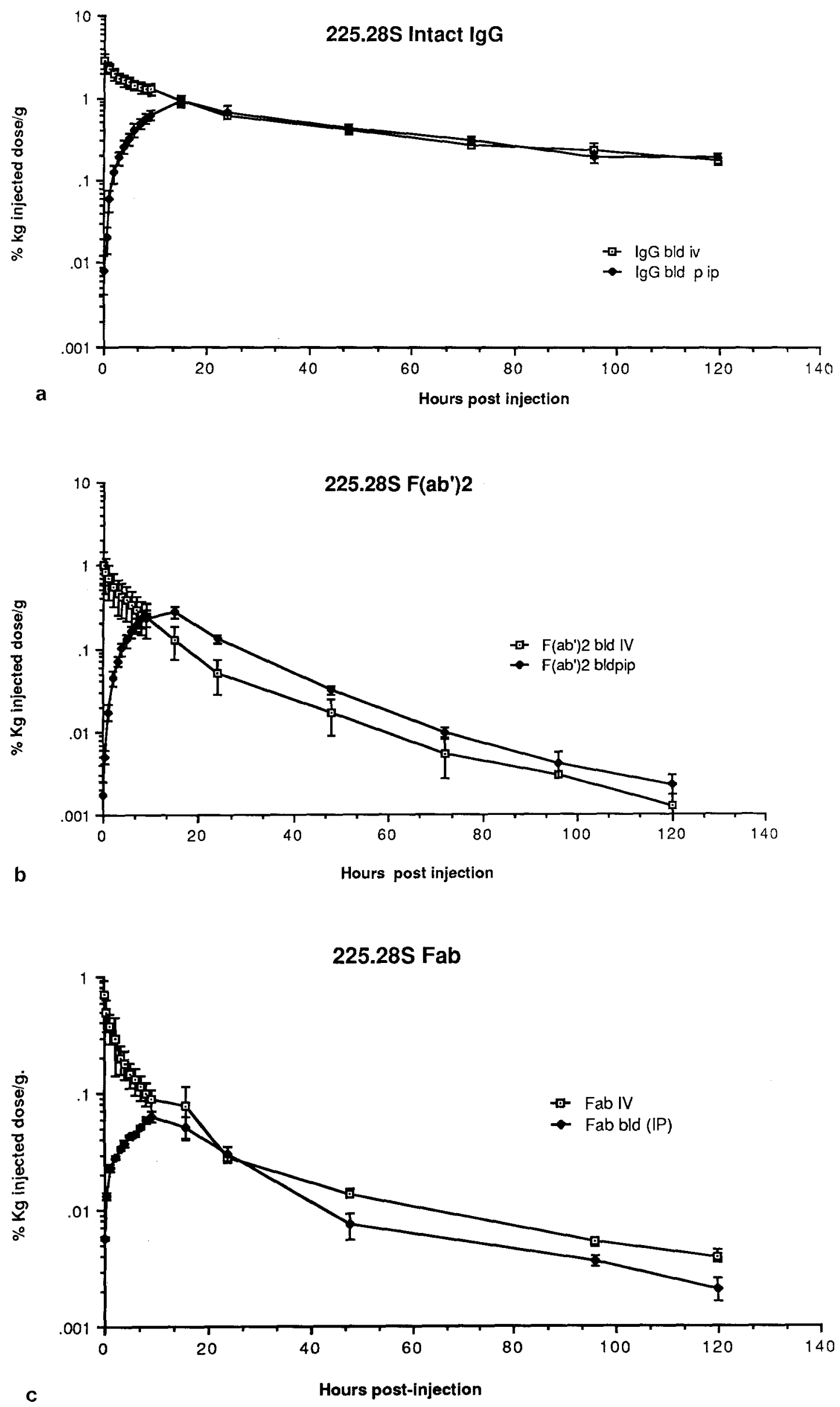


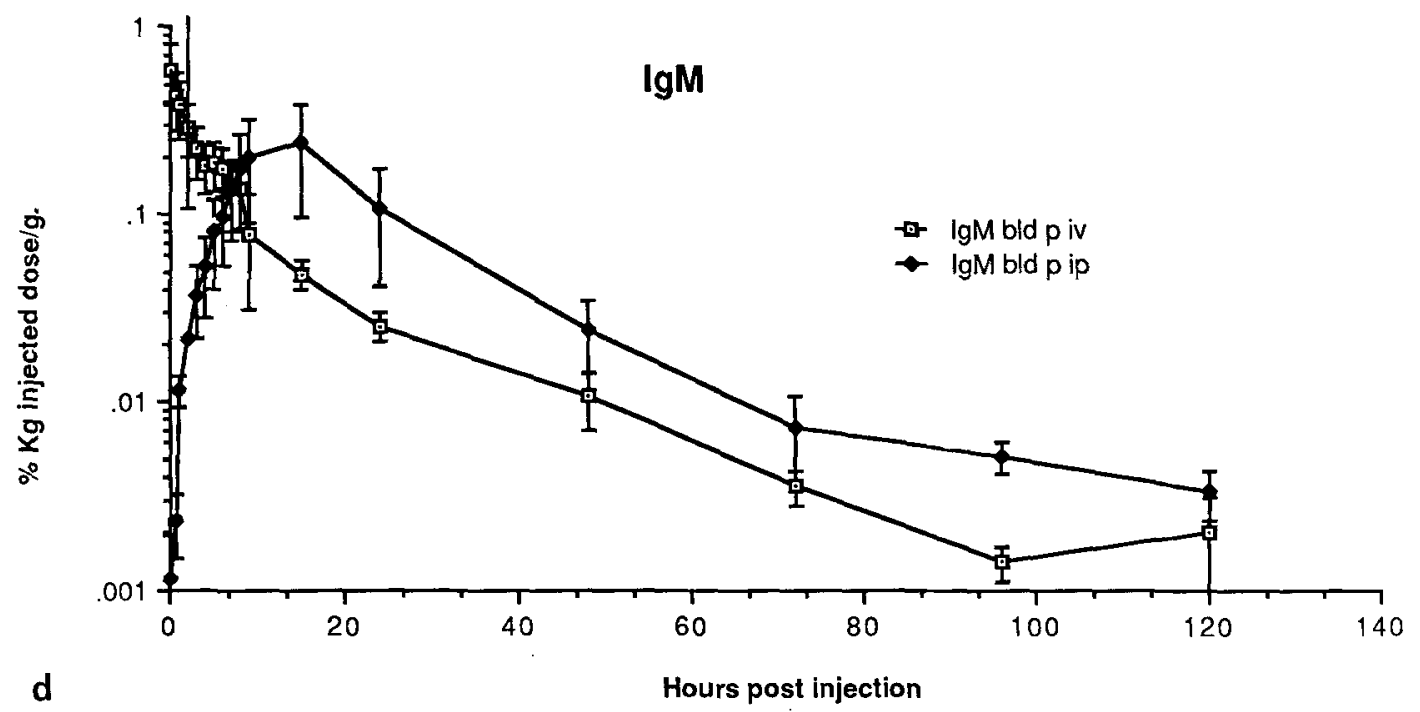

Fig. 4 a-d. (a) Blood levels of intact $225.28 \mathrm{~S} \mathrm{IgG;} \mathrm{(b)} \mathrm{F(ab')})_{2}$ (c) Fab and (d) IgM, FT166 following the i.v. or i.p. injection of equal amounts of radiolabeled antibodies. Note that after approximately 18-24 h, the i.p. and i.v. routes of administration resulted in highly comparable blood levels

Table 2. Absorption rate constants from the peritoneal cavity in normal rats

\begin{tabular}{ll}
\hline Antibody & Absorption rate constant $\pm \mathrm{SEM}\left(\mathrm{h}^{-1}\right)$ \\
\hline Intact 225.28S & $0.098 \pm 0.027$ \\
F(ab') $225.28 \mathrm{~S}$ & $0.118 \pm 0.017$ \\
Fab 225.28S & $0.153 \pm 0.022$ \\
IgM FT166 & $0.157 \pm 0.055$ \\
IgM BA-1 & $0.141 \pm 0.028$
\end{tabular}

Note: There was no statistically significant difference among the mean absorption rate constant for the above reagents ing i.p. than i.v. delivery of antibody (Fig. 8b). Overall tumor/nontumor ratios were 3-6 times higher at $4 \mathrm{~h}$ after i.p. injection than after i.v. delivery. When later times were examined, such as 48 and $120 \mathrm{~h}$ (Fig. $8 \mathrm{c}$ and d), the advantage of i.p. delivery had disappeared and uptakes in essentially all tissues including the i.p. tumors, were comparable by the i.p. and i.v. delivery routes (for the intact $\mathrm{IgG}$ ). That the tumor uptake of 5G6.4 antibody was due to antibody specificity was apparent in the dual-label studies with ${ }^{131} \mathrm{I}$ 5 G6.4 with coinjection of ${ }^{125}$ I UPC-10 i.p. (Table 5). These biodistribution findings substantiated the scan findings shown in Fig. 5 a-d.

Table 3. Mean tissue levels of antibodies or fragments at sacrifice

\begin{tabular}{|c|c|c|c|c|c|c|c|c|}
\hline & \multicolumn{2}{|l|}{ IgG } & \multicolumn{2}{|l|}{$\mathrm{F}\left(\mathrm{ab} \mathrm{b}^{\prime}\right)_{2}$} & \multicolumn{2}{|l|}{ Fab } & \multicolumn{2}{|c|}{$\operatorname{IgM}^{\mathrm{a}}(\mathrm{FT} 166)$} \\
\hline & i.p. & i.v. & i.p. & i.v. & i.p. & i.v. & i.p. & i.v. \\
\hline Liver & $\begin{array}{r}0.0456 \\
\pm 0.0026\end{array}$ & $\begin{array}{r}0.0390 \\
\pm 0.0028\end{array}$ & $\begin{array}{r}0.0066 \\
\pm 0.0030\end{array}$ & $\begin{array}{r}0.0068 \\
\pm 0.0054\end{array}$ & $\begin{array}{c}0.0062 \\
\pm 0.00090\end{array}$ & $\begin{array}{r}0.0155 \\
\pm 0.0036\end{array}$ & $\begin{array}{r}0.0394 \\
\pm 0.0208\end{array}$ & $\begin{array}{r}0.0196 \\
\pm 0.0164\end{array}$ \\
\hline Kidney & $\begin{array}{r}0.1167 \\
\pm 0.0073\end{array}$ & $\begin{array}{r}0.1011 \\
+0.0091\end{array}$ & $\begin{array}{r}0.0078 \\
\pm 0.0012\end{array}$ & $\begin{array}{r}0.0054 \\
\pm 0.0025\end{array}$ & $\begin{array}{r}0.1158 \\
\pm 0.0275\end{array}$ & $\begin{array}{r}0.1637 \\
\pm 0.0272\end{array}$ & $\begin{array}{r}0.1462 \\
\pm 0.0784\end{array}$ & $\begin{array}{r}0.0454 \\
\pm 0.0034\end{array}$ \\
\hline Heart & $\mathrm{ND}$ & ND & ND & ND & $\begin{array}{r}0.0010 \\
\pm 0.0001\end{array}$ & $\begin{array}{r}0.0014 \\
\pm 0.0002\end{array}$ & $\begin{array}{r}0.0017 \\
\pm 0.0005\end{array}$ & ND \\
\hline Lung & $\begin{array}{r}0.2470 \\
\pm 0.0069\end{array}$ & $\begin{aligned} & 0.2580 \\
\pm & 0.025\end{aligned}$ & $\begin{array}{r}0.0100 \\
\pm 0.0027\end{array}$ & $\begin{array}{r}0.0089 \\
\pm 0.0041\end{array}$ & $\begin{array}{c}0.0021 \\
\pm 0.00025\end{array}$ & $\begin{array}{r}0.0025 \\
\pm 0.0003\end{array}$ & $\begin{array}{r}0.0032 \\
\pm 0.0010\end{array}$ & $\begin{array}{r}0.0010 \\
\pm 0.0004\end{array}$ \\
\hline $\begin{array}{l}\text { Diaphragmatic } \\
\text { muscle* }\end{array}$ & $\begin{array}{r}0.0689 \\
\pm 0.0078\end{array}$ & $\begin{array}{r}0.0276 \\
+0.0029\end{array}$ & $\begin{array}{r}0.0047 \\
\pm 0.0030\end{array}$ & $\begin{array}{r}0.0009 \\
\pm 0.0004\end{array}$ & $\begin{array}{r}0.0113 \\
\pm 0.0016\end{array}$ & $\begin{array}{r}0.0010 \\
\pm 0.0001\end{array}$ & $\begin{array}{r}0.0711 \\
\pm 0.0350\end{array}$ & $\begin{array}{r}0.0013 \\
\pm 0.0001\end{array}$ \\
\hline $\begin{array}{l}\text { Skeletal } \\
\text { muscle }\end{array}$ & $\begin{array}{r}0.0177 \\
\pm 0.0020\end{array}$ & $\begin{array}{r}0.0158 \\
\pm 0.0018\end{array}$ & $\begin{array}{r}0.0009 \\
\pm 0.0002\end{array}$ & $\begin{array}{r}0.0007 \\
\pm 0.0004\end{array}$ & $\begin{array}{r}0.0006 \\
\pm 0.0002\end{array}$ & $\begin{array}{r}0.0008 \\
\pm 0.0003\end{array}$ & $\begin{array}{l}\text { back- } \\
\text { ground }\end{array}$ & $\begin{array}{r}0.0052 \\
\pm 0.0053\end{array}$ \\
\hline
\end{tabular}

Data shown are means of $3-5$ animals, and represent time corrected $\% \mathrm{~kg} / \mathrm{dose}$ per $\mathrm{g}$ at 5 days after injection.

a 7 days after injection

* Diaphragmatic muscle radioantibody levels were significantly greater following i.p. delivery $(P<0.001)$ than i.v. delivery for all anti* bodies 

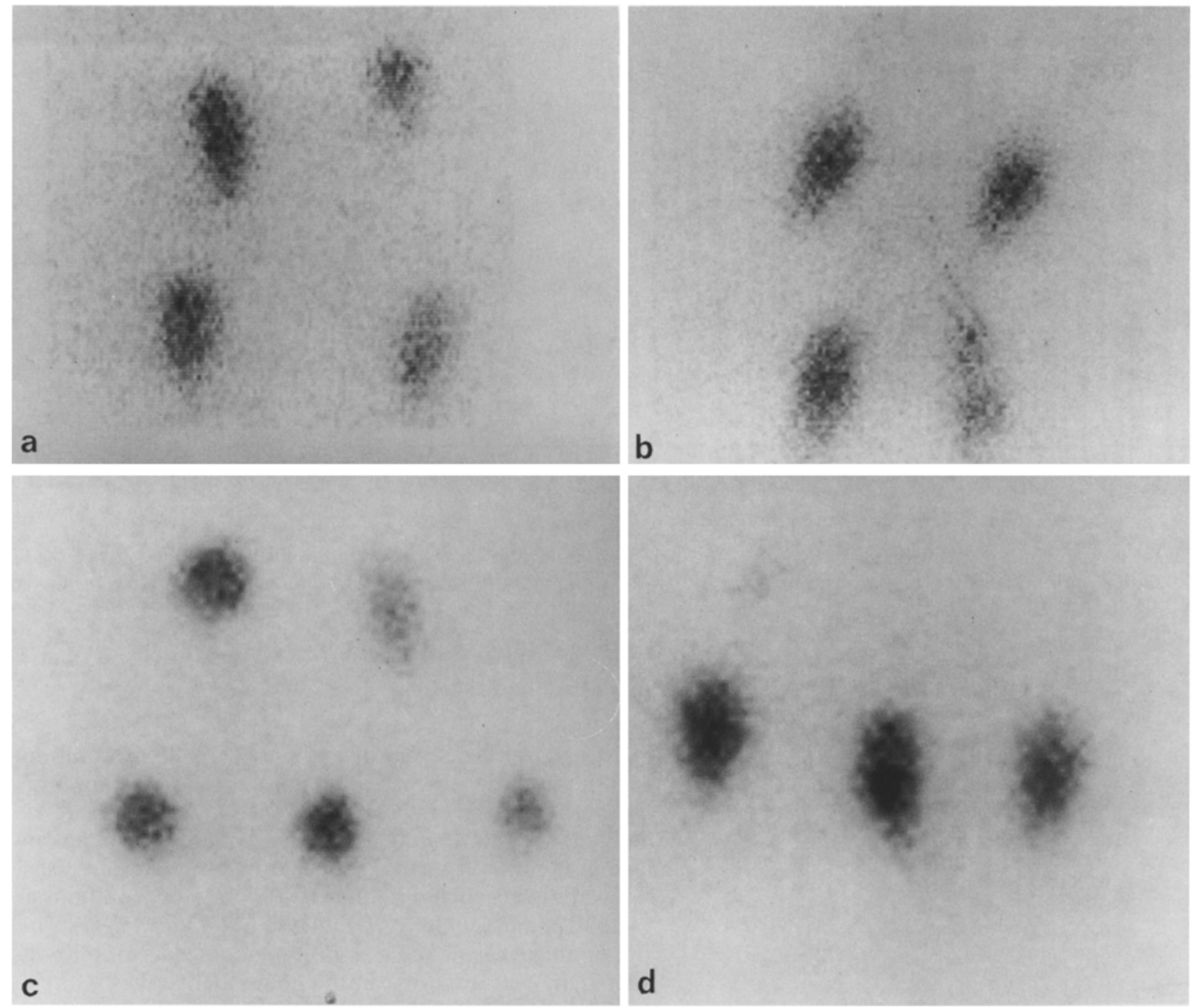

Fig. 5 a-d. Gamma scans $4 \mathrm{~h}$ following i.v. and i.p. administration of ${ }^{131}$ I 5 G6.4 to groups of normal or HTB77 IP3 tumor-bearing nude mice. Mice are prone with heads at bottom of figures. (a) Normal, i.p. antibody delivery; (b) normal i.v. antibody delivery; (c) IP3 tumor, i.p. antibody delivery; (d) IP3 tumor, i.v. antibody delivery. Note fast egress of antibody from the peritoneal cavity in group-a and slower egress in group-c
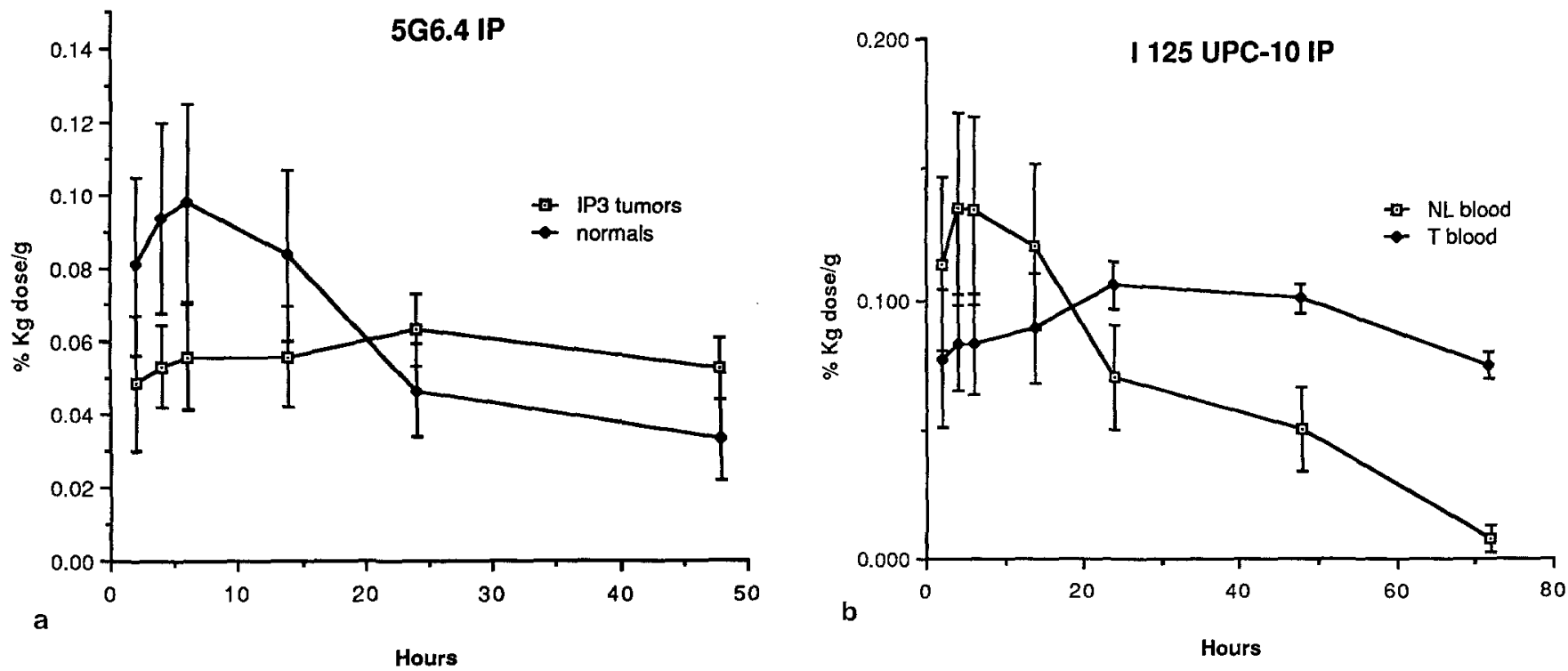

Fig. 6 a-b. The appearance of (a) 5 G6.4 (tumor-specific) and (b) UPC-10 (nonspecific) IgG2aks in the blood following i.p. administration to tumor-bearing animals is shown. Note the higher early blood levels in the normal animals, compatible with their considerably higher absorption rate constants than tumor-bearing animals (Table 6) 
Table 6. Absorption rate constants $\left(\mathrm{h}^{-1}\right)$

\begin{tabular}{ll}
\hline & $5 G 6.4$ \\
Tumor (IP3) & $0.1173 \pm 0.0387(\mathrm{SD})$ \\
Normal & $0.8396 \pm 0.2370(\mathrm{SD})^{\mathrm{a}}$ \\
& $U P C-10$ \\
Tumor (IP3) & $0.1134 \pm 0.0660(\mathrm{SD})$ \\
Normal & $0.8888 \pm 0.7043(\mathrm{SD})^{\mathrm{a}}$
\end{tabular}

Tumor $<$ normal with $P<0.005$

a No difference was seen between 5G6.4 and UPC-10 absorption rate constants

\section{Discussion}

The concept of regional delivery therapy for diseases limited to a particular area of the body is compelling [7]. Our study has demonstrated considerable $\mathrm{Rd}$ advantage ( $\mathrm{Rd}$ $0-9 / 0-9$ ), for all classes and fragments of Igs used in antibody imaging trials to date, and a particularly high $\mathrm{Rd}$ $0-9 / \infty$ for Fab and the FT166 IgM. These data from normal rats showed that the $\mathrm{Rd}$ advantages were elevated in the first $15 \mathrm{~h}$ after i.p. injection of the antibody, and fell after this, indicating that this delivery route would be expected to be superior to the i.v. route for i.p. disease foci. Intact IgG, the obvious first choice for i.p. delivery, has pharmacokinetic properties that suggest it will be less opti- mal for i.p. delivery than its fragments or some IgMs due to its slower clearance from the bloodstream. Despite these pharmacokinetic problems, even intact specific IgG did show an early Rd advantage in i.p. tumors following i.p. delivery, as compared with i.v. delivery.

Although reliably obtaining peritoneal fluid samples from normal rats at later time points was difficult, it appears, where fluid could be obtained, that peritoneal fluid and blood radioantibody levels began to approach one another for all reagents given i.p., and that by $24 \mathrm{~h}$ the blood levels following i.p. or i.v. delivery were nearly identical (Fig. 4 a-d). This indicates that large doses of any radiolabeled antibody given i.p. may potentially result in systemic toxicity, as the peritoneal membrane does not prevent systemic exposure, but only delays it. Our preliminary data suggest that the antibody species given i.p. is not altered by passage from the peritoneal fluid to the blood. The somewhat considerably slower clearance of radioantibody from the peritoneal cavity in i.p. tumor-bearing mice versus normal mice (approximately 8-fold) suggested that the i.p. tumors may offer some degree of protection to systemic exposure, possibly by lymphatic obstruction, but in animals with limited to moderate disease burden, antibody does eventually reach the systemic circulation in considerable quantity. We have recently reported preliminary data from normal nude mice indicating that significant bone marrow radiotoxicity can occur when radioantibody

5G6.4 IP (72 hr data)
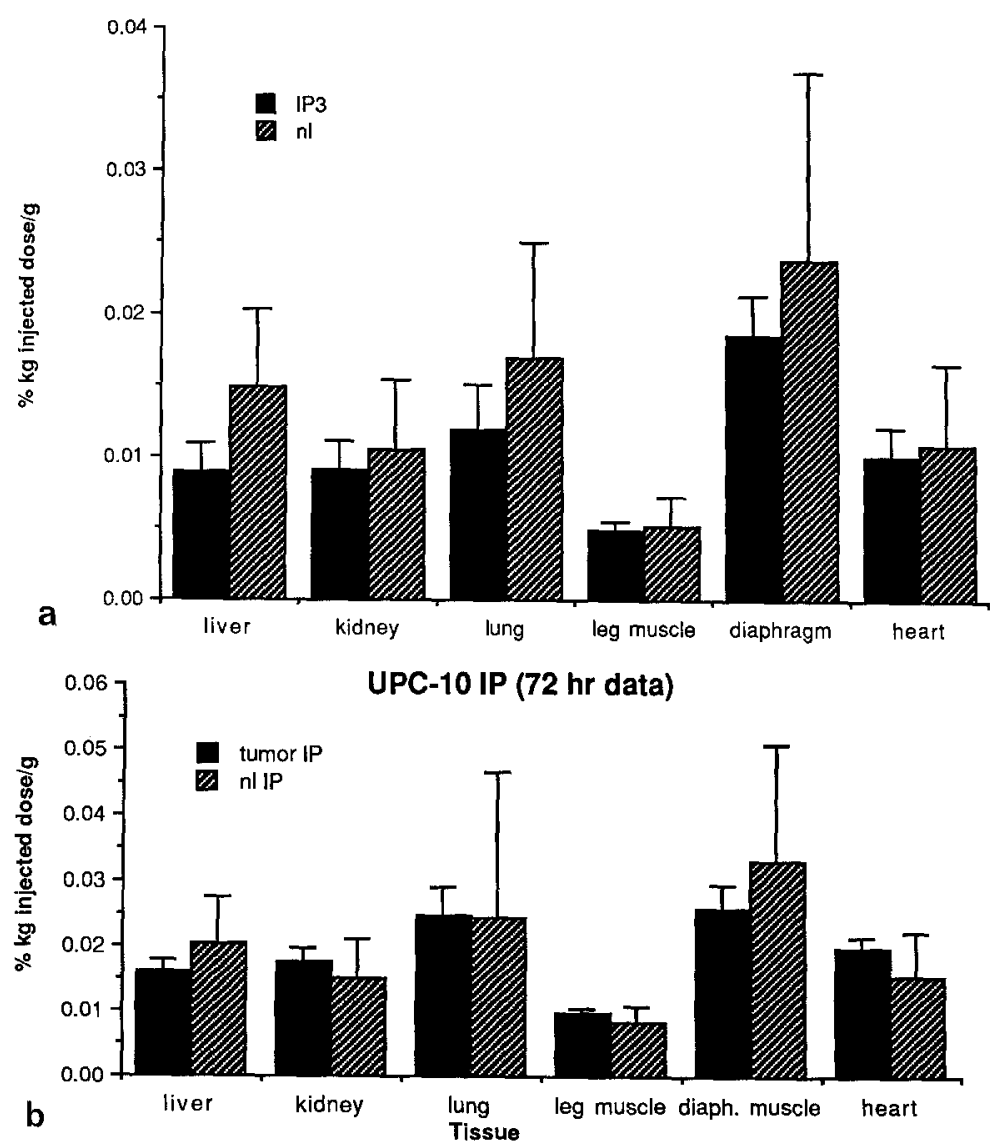

Fig. 7 a-b. Uptake of 5 G6.4 (a) and UPC-10 (b) antibody to normal organs $72 \mathrm{~h}$ after i.p. injection in normal and tumor-bearing animals. Note that despite the slower absorption rate constant in the tumor-bearing animals, that normal tissue uptakes have become quite compa-
rable at this time 


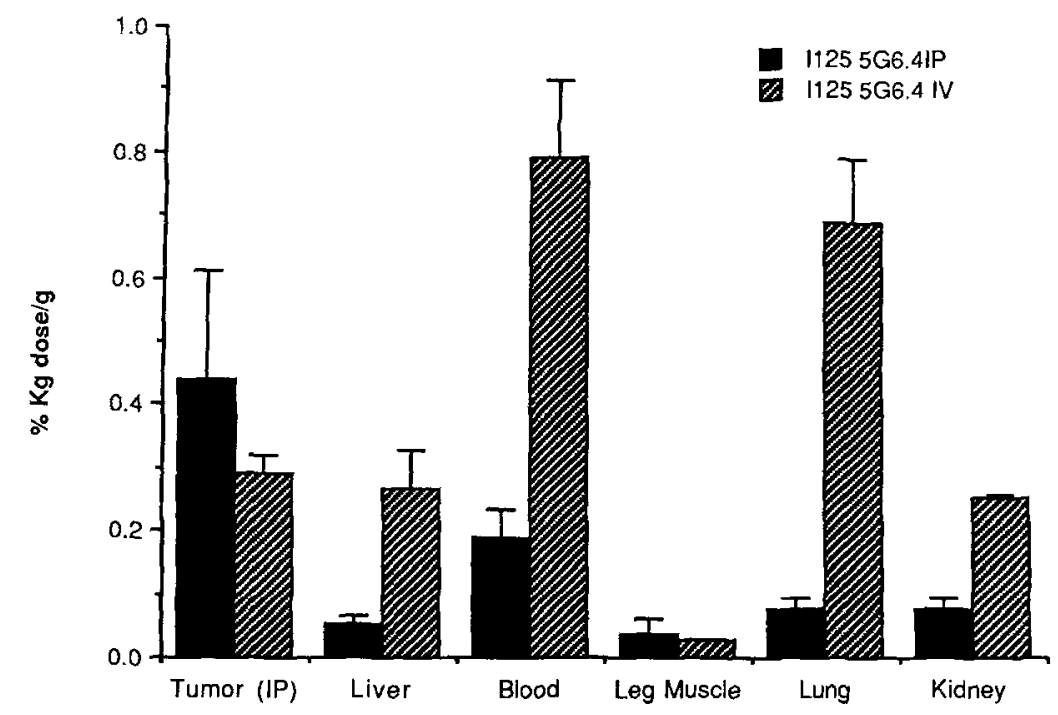

a

Tissue

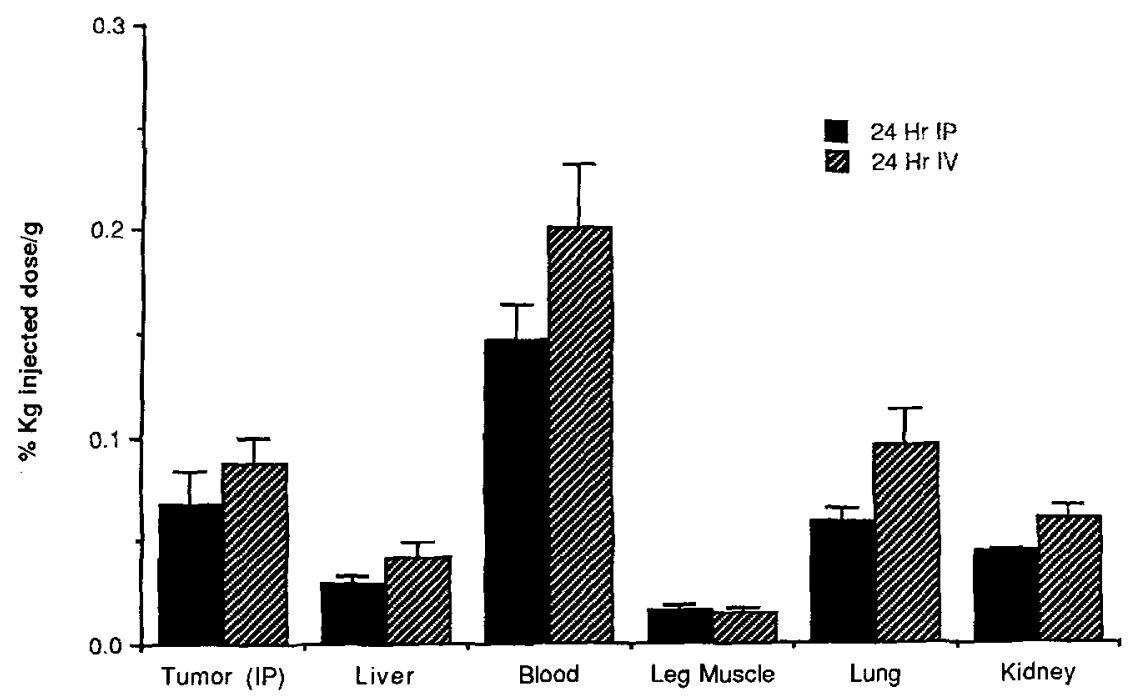

b

Tissue

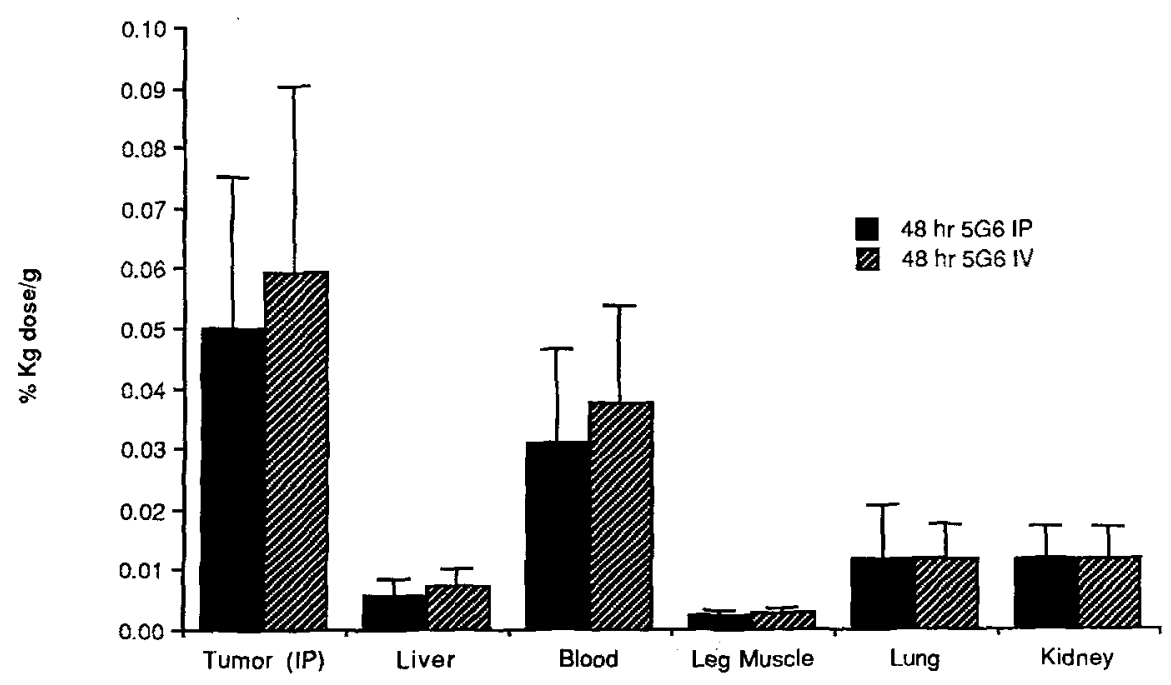

C

Tissue 


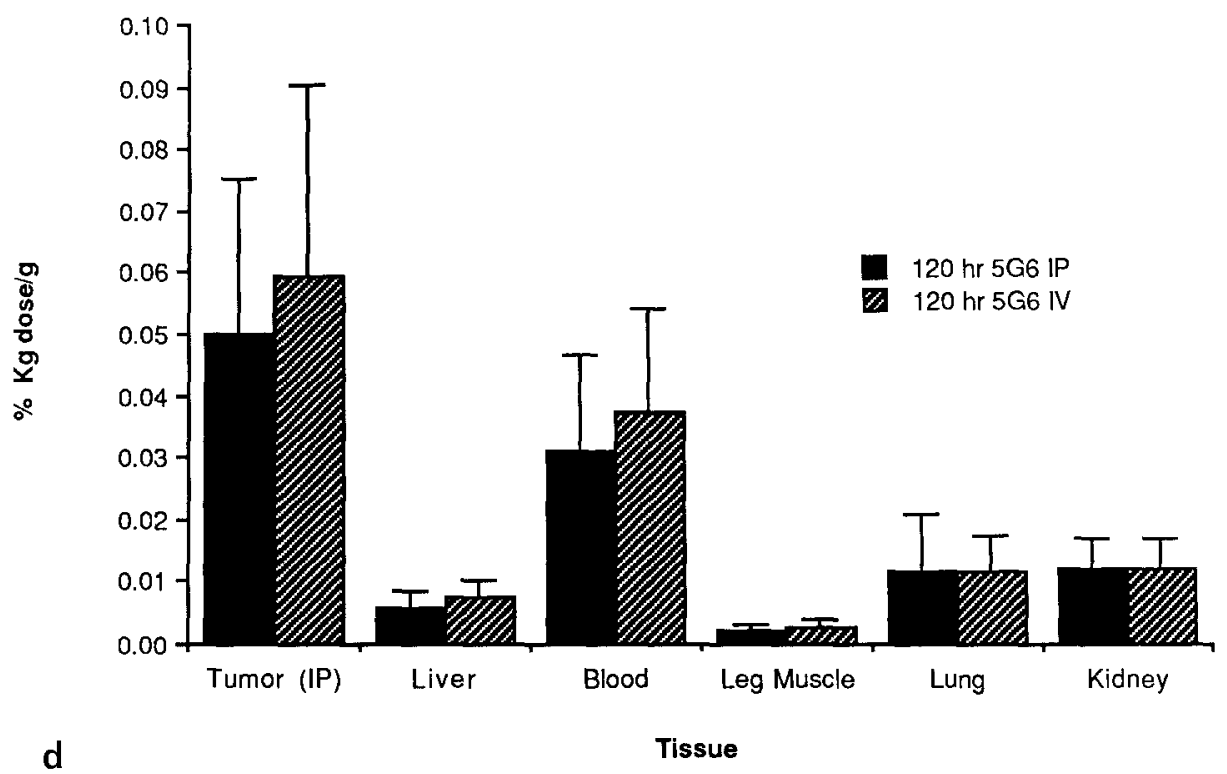

Fig. 8 a-d. HTB77 IP3 tumor and normal tissue uptakes of ${ }^{125} \mathrm{I} 5 \mathrm{G} 6.4$ at $4 \mathrm{~h}$ (a), $24 \mathrm{~h}$ (b), $48 \mathrm{~h}$ (c), and $120 \mathrm{~h}$ (d) following i.p. or i.v. injection. Note the higher absolute tumor uptake at $4 \mathrm{~h}$ after injection by the i.p. route, and the higher relative uptake to tumor extending to $24 \mathrm{~h}$ for the i.p. route. At $48 \mathrm{~h}$ and later, the uptake of antibody was comparable between i.p. and i.v. delivery routes

Table 4. Data at $4 \mathrm{~h}$ (HTB77 IP3 animals)

\begin{tabular}{lcll}
\hline & $\begin{array}{l}\text { i.p. 5G6.4 } \\
(n=6)\end{array}$ & $P$ value & $\begin{array}{l}\text { i.v. 5G6.4 } \\
(n=7)\end{array}$ \\
\hline Tumor $^{\mathrm{a}}$ & $0.183 \pm 0.033$ & $<0.025$ & $0.085 \pm 0.018$ \\
Liver $^{\mathrm{B}}$ & $0.044 \pm 0.008$ & $<0.025$ & $0.078 \pm 0.01$ \\
Blood $^{\mathrm{a}}$ & $0.083 \pm 0.019$ & $<0.1$ & $0.18 \pm 0.052$ \\
Muscle $^{\mathrm{a}}$ & $0.011 \pm 0.001$ & $\mathrm{NS}$ & $0.011 \pm 0.001$ \\
Tumor/blood & $2.369 \pm 0.699$ & $<0.025$ & $0.73 \pm 0.332$ \\
Tumor/muscle & $16.968 \pm 3.725$ & $<0.025$ & $8.035 \pm 1.318$ \\
Tumor/liver & $5.19 \pm 1.371$ & $<0.025$ & $1.074 \pm 0.162$ \\
\hline
\end{tabular}

a Values as $\% \mathrm{~kg}$ injected dose $/ \mathrm{g} \pm \mathrm{SEM}$

is given i.p. and that this toxicity is comparable between the i.p. and i.v. delivery routes [28]. The pharmacokinetic rationale demonstrated in these animal studies also applies to specific antibody delivery in the i.p. human ovarian carcinoma xenograft tumor system using HTB77 IP3 cells. In this model system, the delivery of the 5G6.4 antibody to solid i.p. tumor foci $4 \mathrm{~h}$ after i. p. injection was $50 \%$ more than that of the same antibody given i.v., with tumor/nontumor ratios up to 6 times the i.v. route (Table 4 and Fig. $8 a)$. For free individual tumor cells in the peritoneal cavity, the i.p. delivery advantage $\left(\mathrm{Rd}_{2}\right)$ approached 100 -fold in the first $9 \mathrm{~h}$ for the same dose of antibody given by the i.p. as compared to the i.v. route. Thus one would expect individual tumor cells that are not vascularized to have an even greater $\mathrm{Rd}$ advantage (approaching $\mathrm{Rd}_{2}$ ) than the solid i.p. tumor foci reported in Fig. 8 a-d and Table 4.

From these data, the Rd $0-9 / \infty$ for the Fab of $225.28 \mathrm{~S}$ and the FT166 IgM were noted to be superior to those of the other antibodies and fragments. The BA-1 IgM did not have the same high Rd as the FT166, however. Thus it does not appear generally true that all IgMs are greatly superior to IgGs as regards Rd. The observation that 225.28S Fab had a high $\mathrm{Rd}$ is of considerable interest and was apparently related to the considerably faster systemic clearance of Fab than, for example, intact IgG 225.28S. The essentially identical absorption rate constants from the peritoneal cavity for the varying classes and fragments of Ig was somewhat surprising, based on the reported relationship between molecular weight and peritoneal clearance shown for smaller molecules given i.p. [7]. It should be noted that the heaviest molecule examined in this series was insulin, with a molecular weight of approximately 5,000 [7]. Interestingly, intact IgG (either 225.28 S or UPC-10), the only antibody class used to date reported used in humans for i.p. therapy, had the lowest Rd of any of the antibody moieties tested. In fact, in examining the clearance rates from the peritoneal cavity (Fig. 2), and the absorption rate constants (Table 2), it is apparent that the systemic, not the peritoneal, clearance differences were the main determinants of the differences in $\mathrm{Rd}$ among antibody classes and fragments.

The faster systemic clearance of Fab can be mimicked to improve the Rd of intact IgG, as has been shown in experiments in which we have accelerated the systemic clear-

Table 5. Specificity of i.p. delivery, data at $24 \mathrm{~h}$

\begin{tabular}{lllll}
\hline & $5 \mathrm{G} 6.4$ & $P$ & UPC-10 \\
\hline Tumor $^{\mathrm{a}}$ & $0.091 \pm 0.006$ & $<0.005$ & $0.05524 \pm 0.005$ \\
Liver $^{\mathrm{a}}$ & $0.03 \pm 0.012$ & $\mathrm{NS}$ & 0.03 & \pm 0.002 \\
Blood $^{\mathrm{a}}$ & $0.023 \pm 0.005$ & $<0.025$ & 0.09 & \pm 0.018 \\
Muscle $^{\mathrm{a}}$ & $0.011 \pm 0.001$ & $<0.025$ & 0.024 & \pm 0.003 \\
Tumor/liver & $4.419 \pm 1.261$ & $<0.05$ & 1.812 & \pm 0.129 \\
Tumor/blood & $4.751 \pm 1.215$ & $<0.01$ & 0.679 & \pm 0.124 \\
Tumor/muscle & $9.067 \pm 2.056$ & $<0.025$ & 2.526 & \pm 0.53 \\
\hline
\end{tabular}

a Values as mean $\% \mathrm{~kg}$ injected dose $/ \mathrm{g} \pm \mathrm{SEM}$ following i.p. dual-label coinjection of specific ( ${ }^{131} I$ SG6.4) and nonspecific (125I UPC-10) antibody to nude mice with HTB77 IP3 tumor located i.p.

${ }^{131}$ I 5G6.4 bound approximately $45 \%$ of input counts, and UPC-10 $<1 \%$ to target cells in a $1-\mathrm{h}$ binding assay 
ance of iodinated intact IgG by using a polyclonal antimouse antibody given systemically [21]. This approach, which presumably forms radioactive immune complexes which are then catabolized by the liver, considerably diminishes systemic exposure to radioantibody without measureable impact on i.p. exposure. This approach takes advantage of the fact that little of the polyclonal anti-mouse antibody given systemically will reach the peritoneal cavity, and the fact that clearance from the peritoneal cavity does not appear to be increased by this approach. Alternatively, we have recently reported preliminary data in i.p. ovarian carcinomatosis that relative tumor exposure can be enhanced by lavage of the peritoneal cavity several hours after antibody injection [28].

In our opinion, the $\mathrm{Rd}$ may be most relevant in terms of the incrementally larger dose that may be given regionally, as it most clearly reflects the relative systemic exposure expected for a given i.p. dose. The $\mathrm{Rd}_{2}$, a term to describe the improvement in delivery to the peritoneal space by the i.p. route as compared to peritoneal delivery by the i.v. route, is analogous to the $\mathrm{Rd}$ used by Collins and Dedrick to describe the improvement in tumor exposure to chemotherapeutic agents by the intraarterial delivery route, as compared to the i.v. (systemic) route [6]. In evaluating this term, $F\left(a^{\prime}\right)_{2} 225.28,225.28 \mathrm{~S} \mathrm{IgG}$, and FT166 IgM gave comparable, approximately 100 -fold, improvements in delivery to the peritoneal cavity by the i.p. route as compared with the i.v. route, $\left(\operatorname{Rd}_{2} 0-9 \mathrm{~h}\right)$ with the Fab producing a slightly lesser, but still marked improvement $\left(\mathrm{Rd}_{2} 0-9 \mathrm{~h}=\right.$ approximately 60$)$.

Tissue levels of antibody activity in the mouse studies indicated that the i.p. delivery route resulted in lower systemic exposure to radiolabeled antibody early on (as judged by blood levels), but later, the nontarget tissue levels were quite similar to those achieved following i.v. delivery. The radioantibody levels in the diaphragm were always higher following i.p. delivery than those achieved following i.v. delivery at 5-7 days following injection. This higher diaphragmatic uptake was presumably due to the intimate contact of the antibody and hemidiaphragm during antibody egress from the peritoneal cavity (possibly through lymphatics in the diaphragm) and suggests that the entire peritoneal surface may have high exposure at these later time points, even if no fluid is available for sampling. The comparable later systemic exposure levels for the various antibodies given i.v. or i.p. in normal rats, indicate that the i.p. route, although delivering more radioactive antibody to the peritoneal space, does not eliminate, but does delay systemic exposure, and that systemic toxicity certainly may result following i.p. radioimmunotherapy [30].

While the pharmacokinetic data in normal rats are of interest, of greater practical relevance is that this study also showed that the high i.p. Rd advantage seen with monoclonal antibodies can be translated successfully into higher uptakes of specific antibody into i.p. ovarian carcinoma tumor foci than following i.v. administration (at early time points after injection). This advantage disappeared at later times, which probably explains our preliminary unsuccessful attempts to detect enhanced delivery to i.p. as compared to extraperitoneal ovarian carcinoma xenographs after i.p. radioantibody delivery when the tumors were examined at 7 days after monoclonal antibody injection [22]. Of note is that the absorption rate constant for $\operatorname{IgG}$ in nor- mal mice was 7-8 times larger than in tumor-bearing mice, suggesting the tumor may make regional delivery more rational, though not eliminating systemic exposure (Fig. 7a and $b$ ). That these pharmacokinetic and localization data following i.p. antibody delivery are relevant to radioimmunotherapy is indicated by our recent demonstration in an i.p. human colon carcinoma xenograft system that i.p. radioimmunotherapy with the ${ }^{131}$ I 5 G6.4 monoclonal is significantly superior to the i.v. delivery route [29].

In conclusion, the i.p. route of radioantibody delivery offers a significant enhancement in antibody delivery to the peritoneal space in normal and tumor-bearing animals as compared to the i.v. route. Fab, $F\left(a^{\prime}\right)_{2}$, and some IgMs appear pharmacokinetically superior to intact IgGs for i.p. delivery with the Fab being most superior pharmacokinetically. Naturally, evaluation of these and other antibody fragments in animals with i.p. tumor will be of additional interest as well as varying injected protein dose and volume. These pharmacokinetic data support the concept that the i.p. injection route is a rational means to deliver specific monoclonal antibodies to i.p. tumor foci. These data should be very useful in planning diagnostic and therapeutic studies using this delivery route.

Acknowledgements. Michele Curro's excellent typing assistance is appreciated. The technical assistance of Jon Johnson, Phil Sherman, Gayle Jackson, Martin Strnat, Joe Wissing, and Steve Kronberg was very helpful. This work was supported by $\mathrm{NCI}$ ROI CA41531-02 and CA33802-04 awarded RW by the PHS, DHHS.

\section{References}

1. Abramson CS, Kersey JH, LeBien TW (1981) A monoclonal antibody (BA-1) reactive with cells of human B-lymphocyte lineage. J Immunol 126: 83

2. Bast RC, Feeney M, Lazaurs H, et al. (1981) Reactivity of a monoclonal antibody with human ovarian carcinoma. J Clin Invest 68: 1331-1337

3. Burchiel SW, Khaw BA, Rhodes BA, et al. (1982) Immunopharmacokinetics of radiolabelled antibodies and their fragments. In: Burchiel SW, Rhodes BA (eds) Tumor imaging. Masson Publishing, New York, pp 125-140

4. Chatterjee SK, Bhattacharya M, Barlow JJ (1984) Murine monoclonal antibodies against galactosyltransferase from the ascites of ovarian cancer patients. Cancer Res 44: 5725 -5732

5. Colcher D, Zalutsky M, Kaplan W, et al. (1983) Radiolocalization of human mammary tumors in athymic mice by a monoclonal antibody. Cancer Res 43: 736-742

6. Collins JM, Dedrick RL (1982) Pharmacokinetics of anticancer drugs. In: Chabner B (ed) Pharmacologic principles of cancer treatment. W. B. Saunder Co., Philadelphia, pp 77-99

7. Dedrick RL, Myers CE, Bungay PM, et al. (1978) Pharmacokinetic rationale for peritoneal drug administration in the treatment of ovarian cancer. Cancer Treat Rept 62:1-11

8. Ey $\mathrm{P}$, Prowse $\mathrm{S}$, Jenkins $\mathrm{C}$ (1978) Isolation of pure $\mathrm{IgG}_{1}$, $\mathrm{IgG}_{2 \mathrm{a}}$, and $\mathrm{IgG}_{2 \mathrm{~b}}$ from mouse serum using protein A-Sepharose. Immunochemistry $15: 429-436$

9. Granowska M, Shepherd J, Britton KE, et al. (1984) Ovarian cancer: Diagnosis using I-123 monoclonal antibody in comprison with surgical findings. Nucl Med Commun 5: 485-499

10. Hammersmith Oncology Group (1984) Antibody-guided irradiation of malignant lesions: Three cases illustrating a new method of treatment. Lancet I 8392: 1441-1443

11. Jones RB, Collins JM, Myers CG, et al. (1981) High-Volume intraperitoneal chemotherapy with methotrexate in patients with cancer. Cancer Res 41:55-59

12. Laemmli VK (1970) Cleavage of structural proteins during assembly of the head of bacteriophage T4. Nature 222: 680-685 
13. Markwell MAK (1982) A new solid-state reagent to iodinate proteins. I. Conditions for the efficient labeling of antiserum. Anal Biochem 125: 427-432

14. Mason DW, Williams AF (1980) The kinetics of antibody binding to membrane antigens in solution and at the cell surface. Biochem J 187: 1-20

15. Moldofsky PJ, Powe J, Mulhern CB, et al. (1983) Metastatic colon carcinoma detected with radiolabeled $\mathrm{F}\left(\mathrm{ab}^{\prime}\right)$, monoclonal antibody fragments. Radiology 149: 549-555

16. Porter RR (1959) The hydrolysis of rabbit gamma globulin and antibodies with crystalline papain. Biochem J 73: 119

17. Pressman D, Day ED, Blau M (1957) The use of paired labeling in the determination of tumor-localizing antibodies. Cancer Res 17: 845-850

18. Rosenshein N, Blake D, McIntyre PA, et al. (1978) The effect of volume on the distribution of substances instilled into the peritoneal cavity. Gynecol Oncol 6:106-110

19. Sedman AJ, Wagner JN (1974) AUTOAN, a decision-making pharmacokinetic computer program. College of Pharmacy, The University of Michigan, Ann Arbor, MI, p 102

20. Speyer JL, Collins JM, Dedrick RL, et al. (1980) Phase I and pharmacological studies of 5-fluorouracil administered intraperitoneally. Cancer Res 40: 567-572

21. Wahl RL, Fisher S (1987) Intraperitoneal delivery of monoclonal antibodies: Enhanced regional delivery advantage using intravenous unlabeled antimouse antibody. Nucl Med Biol 14: $611-615$

22. Wahl RL, Piko C (1985) Intraperitoneal (IP) delivery of radiolabeled monoclonal antibody to IP-induced xenografts of human ovarian cancers. Proc AACR 26: 298

23. Wahl RL, Parker CW, Philpott GW (1983) Improved radioimaging and tumor localization with monoclonal $\mathrm{F}(\mathrm{ab})_{2}$. J Nucl Med 24: 316-325

24. Wahl RL, Geatti O, Fisher S (1985) Intraperitoneal delivery of monoclonal antibodies: Influence of class and fragmentation on kinetics and intraperitoneal dosing advantage. $\mathrm{J}$ Nucl Med 26 (5): 114
25. Wahl RL, Geatti O, Liebert M, et al. (1985) Radioimmunoimaging and localization of human ovarian carcinoma xenografts. Radiology 157 (P): 99

26. Wahl RL, Liebert M, Carey JE, Jackson G (1985) Quality control of radiolabeled monoclonal antibodies: Immunologic and radiochemical. Cancer Drug Delivery 2 (3): 236

27. Wahl RL, Liebert M, Biesman B, Roberts J, Jackson G, Kronberg S, Laino L (1986) Production and characterization of a murine monoclonal antibody reactive with ovarian and other epithelial carcinomas. Proc AACR 27: 355

28. Wahl RL, Fisher S, Sherman P (1987) Intraperitoneal delivery of radiolabeled monoclonal antibodies: Effect of peritoneal lavage on intraperitoneal tumor uptake. J Nucl Med 28 (4): 715

29. Wahl RL, Liebert M, Fisher S, Boland R (1987) Enhanced radioimmunotherapy of intraperitoneal human colon cancer xenografts by intraperitoneal monoclonal antibody delivery. Proc AACR 28: 438

30. Wahl RL, Liebert M, Fisher S; Laino L (1987) The toxicity of radiolabeled antibodies. J Nucl Med 28 (4): 684

31. Wahl RL, Liebert M, Fisher S, Sherman P, Jackson G, Laino L, Wissing J (1987) Radioimmunotherapy of human ovarian carcinoma xenografts: Preliminary evaluation. Proc AACR 28: 384

32. Wahl RL, Geatti O, Liebert M, Wilson B, Shreve P, Beers BA (1987) The kinetics of interstitially administered monoclonal antibodies for purposes of lymphoscintigraphy. J Nucl Med 28: $1736-1744$

33. Wilson BS, Imai K, Natali PG, et al. (1981) Distribution and molecular characterization of a cell surface and cytoplasmic antigen detectable in human melanoma cells with monoclonal antibodies. Int J Cancer 28: 293-300

Received December 2, 1987/Accepted December 30, 1987 